\title{
Development and characterization of stainless steel fiber-based copper-free brake liner formulation: A positive solution for steel fiber replacement
}

\author{
Vijay $\mathbf{R}^{1}$, D. Lenin SINGARAVELU ${ }^{1, *}$, R. JAYAGANTHAN ${ }^{2}$ \\ ${ }^{1}$ Department of Production Engineering, National Institute of Technology, Tiruchirappalli 620015, Tamil Nadu, India \\ ${ }^{2}$ Department of Engineering Design, Indian Institute of Technology Madras, Chennai 600036, Tamil Nadu, India \\ Received: 22 November 2017 / Revised: 09 August 2018 / Accepted: 21 January 2019 \\ (C) The author(s) 2019.
}

\begin{abstract}
This study deals with the development of drum brake liner for a multi-utility vehicle possessing a hydraulic brake system by varying 7 weight $\%$ of steel fiber and stainless steel fiber each, in friction composite formulations. The developed friction composites were tested for physical, chemical, corrosion, mechanical, thermal properties, and tribological characteristics, under near-actual conditions using an inertia dynamometer as per industrial standards. Finite element analysis software (ANSYS) analysis was performed to show the thermal stress distribution of the developed friction composites at the maximum temperature rise due to heat generated during brake stops, and an extensive evaluation method was used to rank the composites. The study concludes that the brake factor of the stainless steel fiber-based friction composite produces stable performance in all conditions with a lower liner temperature rise of $340{ }^{\circ} \mathrm{C}$ and lower thermal stress at 4.255294 MPa. However, the steel fiber-based composites produced high performance at the beginning but deteriorated after a certain period due to higher levels of corrosion and a high temperature rise of $361{ }^{\circ} \mathrm{C}$ resulting in a negative fade $(-0.84 \%)$ and more thermal stress $(5.619102 \mathrm{MPa})$. The primary plateau, secondary plateau, back transfer of drum wear debris, and the distribution of constituents on the worn surface of the developed composites in a resin matrix were identified and studied using a scanning electron microscope (SEM) equipped with energy-dispersive spectroscopy.
\end{abstract}

Keywords: stainless steel fiber; steel fiber; brake liner; friction composite

\section{Introduction}

The brake is a mechanical component for converting kinetic energy into thermal energy using friction [1]. A brake system is classified as a drum brake or disc brake based on its mating surface (construction). Drum brakes contain a set of brake liners made up of friction material bonded or riveted to a curvilinear backing plate and pressed against a rotating part called the rotating drum. In the case of a disc brake system, a disc rotates with the wheel and when the brakes are applied, a set of pads made up of friction material bonded with a backing plate present in the caliper assembly actuate towards the disc, causing the vehicle to stop. Due to energy transformation in this zone, heat dissipation takes place in the form of conduction and convection. This heat also causes the formation of friction film at the mating interface by degrading low, thermally stable, and polymeric ingredients [2]. Thus, the brake friction materials are a cocktail of 15 to 20 ingredients required to achieve desired characteristics like stable friction, low wear rate, low noise, and improved performance in all environmental conditions. Based on the function of

* Corresponding author: D. Lenin SINGARAVELU, E-mail: dlenin@nitt.edu 
the ingredients, they are broadly classified into four main categories namely: binders, fibers, friction modifiers, and fillers. Asbestos based friction composites were banned by the Environmental Protection Agency in 1989 because of its carcinogenic nature. Presently, copper usage in brake friction material formulations has reduced and it is on the verge of being banned in some developed countries because it is to aquatic life [2]. Thus, non-asbestos based friction composites are currently widely used, and these are further classified as: semi-metallic, low metallic and organic. However, the need for improved performance under harsh and heavy load conditions has led to the use of hybrid friction composites, which are a combination of two or more fibers. The fibers can be metallic fibers, organic fibers, glass fibers, ceramic fibers, carbon fibers, etc. There are some findings in the literature which incorporate steel fibers in the friction composites. Bijwe and Kumar [3] studied the effect of steel wool contents in organic brake friction composites by developing three different brake pads, varying steel wool, and compensating with synthetic barites. The developed friction composites were tested for tribological and thermal conductivity behavior as per industrial standards. It was observed that an increase in steel wool content in the friction composite increases the thermal conductivity and frictional properties, but this was accompanied with increased disc wear. Jang et al. [4] investigated the influence of copper, steel, and aluminum fibers on the friction and wear characteristics of brake friction materials. It was shown that steel fiber-based friction materials create rotor wear and disc thickness variation, thus leading to brake judder. Park et al. [5] made a comparative study on the tribological behavior of brake friction materials made with and without steel fibers. It was proved that steel fiber-based friction materials result in negative fade, causing more noise and damage to the rotor. Fade is a phenomenon in which the frictional properties deteriorate with increase in temperature. Though steel fiber-based friction materials have a good service life, brake friction composites were developed using steel fiber, brass fiber, and copper powder, and the effect of these constituents on the coefficient of friction were studied on the reduced scale prototype friction tester [6]. It was proved that metallic contents in the friction composites enhance the friction and wear characteristics, especially with copper powder-based friction composites; also, the steel fiber-based friction composite has a lower wear rate under low speed and low pressure conditions. The effect of the thermal stability and thermal conductivity of steel fibers on fade and recovery characteristics of a semi-metallic disc brake pad was studied, and it was concluded that higher steel fiber-based brake pads produced more friction, also leading to more disc wear [7]. Recovery is defined as the property of regaining the friction properties upon cooling the braking surface. Corrosion plays a crucial role in performance deterioration of friction materials. Though steel fiber produces good frictional properties under certain dry conditions, during wet conditions, there is formation of a rust layer which causes poor performance [8]. From the literature discussed, it is apparent that steel fiber in friction composites causes higher levels of mating surface wear (disc thickness variations), leading to noise. It also causes corrosion on the surface of the friction materials upon prolonged exposure to wet conditions. It is clear from the literature that no alternative has been studied in comparison with the steel to provide a positive solution to these problems. Hence, stainless steel fibers were chosen as an alternative to steel fibers in the development of friction composites in this study. This study deals with the use of stainless steel fiber in drum brake liner formulation for application in multi-utility vehicle. The physical, chemical, thermal, corrosive, and tribological characteristics of stainless steel fiber-based friction composites are investigated and compared with those of steel fiber-based friction composite.

\section{Experimental methods}

\subsection{Materials}

Stainless steel fiber of American Iron and Steel Institute (AISI) 434 grade and steel fiber of K-15 grade were chosen as the variable ingredient among other ingredients, which are presented in subsequent sections as parental ingredients for the friction composite formulation. The specifications as obtained from the raw material suppliers of steel and stainless steel fibers are given in Table 1. It is inferred that Figs. 1(a) and 1(b) show scanning electron microscope (SEM) images of steel fiber and stainless steel fiber showing 
Table 1 Specification of steel fiber (K-15 Grade) and stainless steel fiber (SS-434 Grade).

\begin{tabular}{|c|c|c|c|c|}
\hline S/No. & Property & Unit & $\begin{array}{c}\text { Steel fiber } \\
(\mathrm{K}-15 \text { Grade })\end{array}$ & Stainless steel fiber (SS-434 Grade) \\
\hline 1 & Appearance & Visual & $\begin{array}{l}\text { Grey with little } \\
\text { silver color }\end{array}$ & Bright silver color \\
\hline 2 & Microstructure & Visual & $\begin{array}{l}\text { Ferrite with } \\
\text { pearlite }\end{array}$ & $\begin{array}{l}\text { Ferrite with distributed fine carbide } \\
\text { structure }\end{array}$ \\
\hline 3 & Micro Vickers hardness (HV 0.1) & - & 285.2 & 224.4 \\
\hline 4 & Acetone extraction & $\%$ & $0.15 \max$. & $0.2 \max$. \\
\hline 5 & Loose Bulk Density (Funnel method) & $\mathrm{g} / \mathrm{cc}$ & $0.75-1.10$ & $0.60-1.00$ \\
\hline 6 & $\begin{array}{l}\text { Tap bulk density } 50 \text { grams sample/ } 10 \text { min or } \\
\text { ( } 250 \text { Tap) using the densometer method }\end{array}$ & $\mathrm{g} / \mathrm{cc}$ & $01.00-1.60$ & $0.90-1.30$ \\
\hline 7 & Specific gravity & - & $7.90-8.40$ & $7.8-8.1$ \\
\hline \multirow[t]{11}{*}{8} & \multicolumn{4}{|c|}{ Particle size sample: 100 grams, Sample/15 min, sieve analysis-Ro-tap } \\
\hline & i) $+14 \mathrm{BSS}$ & $\%$ & Nil & - \\
\hline & ii) $-14+40 \mathrm{BSS}$ & $\%$ & $8.0-16.0$ & - \\
\hline & iii) $-40+60 \mathrm{BSS}$ & $\%$ & $15.0-25.0$ & - \\
\hline & iv) $-60+100$ & $\%$ & $15.0-25.0$ & - \\
\hline & v) $-100(\operatorname{Pan})$ & $\%$ & $40.0-60.0$ & - \\
\hline & i) $+16 \mathrm{BSS}$ & $\%$ & - & $0 \sim 2$ \\
\hline & ii) $-16+30 \mathrm{BSS}$ & $\%$ & - & $0 \sim 10$ \\
\hline & iii) $-30+60 \mathrm{BSS}$ & $\%$ & - & $5 \sim 20$ \\
\hline & iv) $-60+120 \mathrm{BSS}$ & $\%$ & - & $5 \sim 25$ \\
\hline & v) $-120(\operatorname{Pan})$ & $\%$ & - & $55 \sim 75$ \\
\hline \multirow[t]{9}{*}{9} & Chemical composition for reference only & & & \\
\hline & i) $\mathrm{C}$ & $\%$ & $0.09-0.12$ & $0.08 \max$ \\
\hline & ii) $\mathrm{Mn}$ & $\%$ & $0.30-1.00$ & $1.00 \max$ \\
\hline & iii) $\mathrm{Si}$ & $\%$ & $0.08-0.15$ & 1.00 max. \\
\hline & iv) $\mathrm{P}$ & $\%$ & 0.05 max. & $0.04 \max$ \\
\hline & v) $\mathrm{S}$ & $\%$ & $0.05 \max$. & - \\
\hline & vi) $\mathrm{Ni}$ & $\%$ & - & $0.50 \max$ \\
\hline & vii) $\mathrm{Cr}$ & $\%$ & - & $16.00-18.00$ max. \\
\hline & viii) Mo & $\%$ & - & $0.90-1.4$ max. \\
\hline
\end{tabular}

the respective diameters. Figure 1(c) shows the Weibull distribution plot for the diameters of the fibers in which the standard deviation of stainless steel fibers are 8.302 and $27.25 \mu \mathrm{m}$ for steel fibers. Thus, it is inferred that there is more variation in diameter for steel fibers. This variation is mainly due to hardness that causes a brittle nature which leads to difficulty producing the fibers.

\subsection{Development of the composites}

The developed friction composite for drum brake liner consists of sixteen ingredients: one variable ingredient (7 weight \%), being steel fiber or stainless steel fiber, and fifteen parental ingredients (93 weight \%). The parental ingredients are: fibers (inclusive of additives) (10 weight \%)-aramid, hydrated lime powder, and arbocel; binders (primary and secondary with additives) (21 weight \%)-straight phenolic resin, NBR, crumb rubber, and sulfur; friction modifiers (lubricants and abrasives) (19 weight \%)-iron sulfide, synthetic graphite, and zirconium silicate; fillers (functional and inert) (43 weight \%)-exfoliated vermiculite, friction 

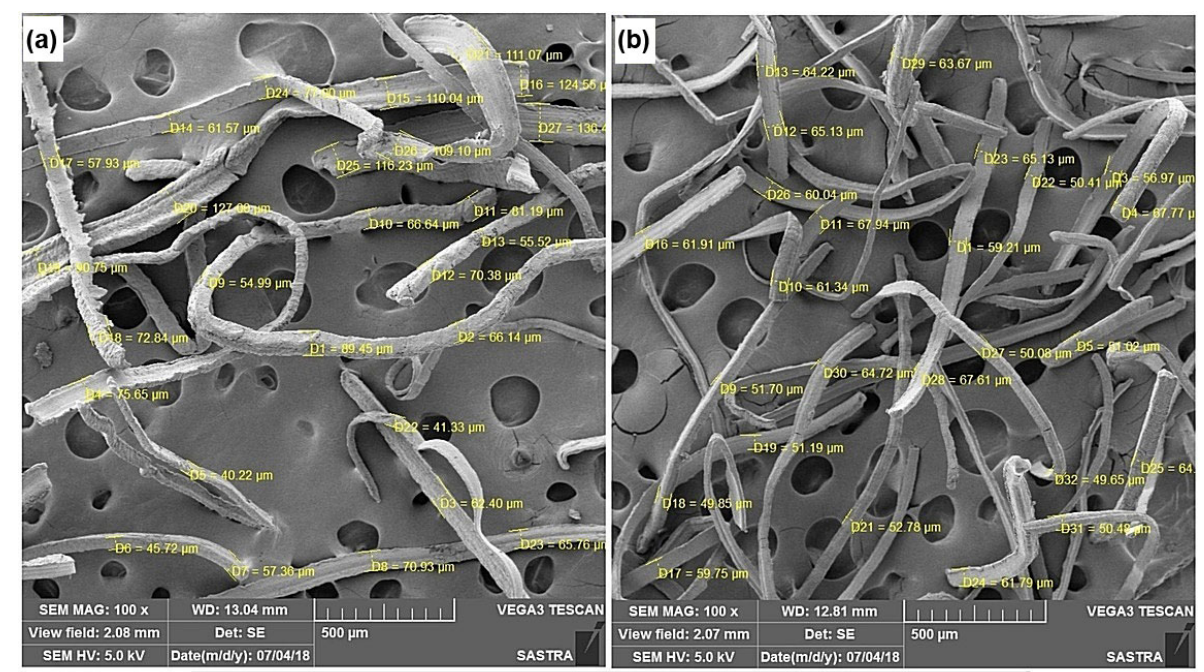

(c) Probability plot of diameter $(\mu \mathrm{m})$ stainless steel fiber, steel fiber

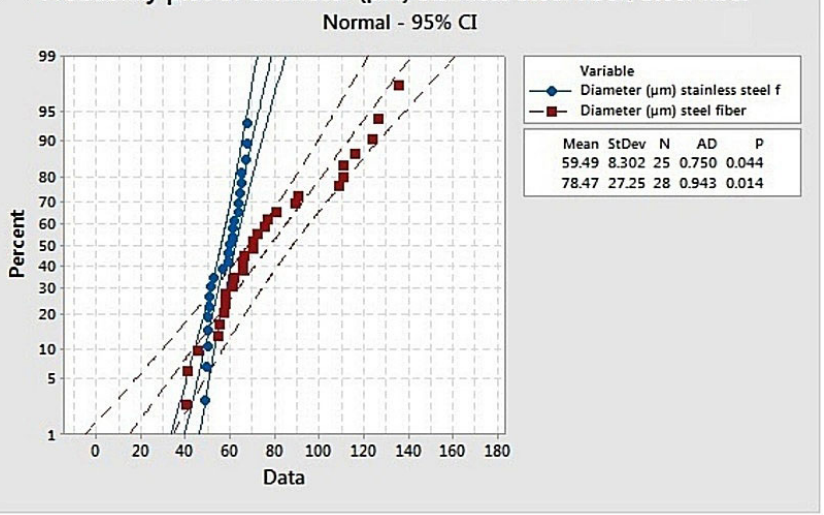

Fig. 1 SEM images of (a) steel fiber, (b) stainless steel fiber, and (c) weibull distribution for the fiber diameters.

dust, synthetic barites, mica, and calcium carbonate. Based on the variable ingredients, steel and stainless steel fibers, the developed friction composites are named FM01 and FM02 respectively, and photographs are shown in Fig. 2. The development of the friction composites was done as per the conventional manufacturing process that included mixing in a plough shear mixing machine. This is followed by being preformed, then curing in a compression molding machine for condensation polymerization of the resin mixture. To remove residual stress, post curing is done as a step baking process in a hot air oven. The details of the process are given in Appendix I.

\subsection{Physical, chemical, mechanical, and thermal characterizations of the developed friction composites}

The physical, chemical, mechanical, and thermal
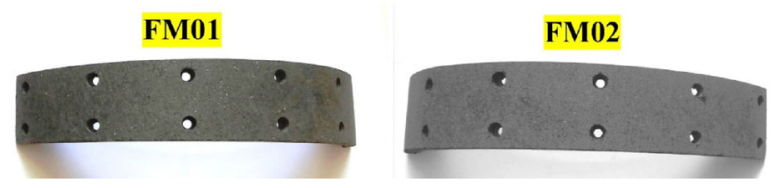

Fig. 2 Developed friction composites (FM01 and FM02).

properties of the composites were determined as per industrial standards. Three samples were tested in each test to check the consistency of the results, and a $5 \%$ standard error was accepted as per industrial standards. The calibrations of the testing equipment was done as per the national traceability standards by NABL certified laboratories. Specific gravity was measured using specific gravity apparatus that works on the Archimedes principle. Hardness was measured on a Rockwell hardness testing machine based on the 'L' scale with a steel ball indenter of $6.35 \mathrm{~mm}$ diameter and applied load of $600 \mathrm{~N}$. The cross breaking strength was measured for the developed friction composite 
by cutting a sample of width $50 \mathrm{~mm}$ at the center at a room temperature not exceeding $40{ }^{\circ} \mathrm{C}$. The load was applied squarely across the width of the specimen using a third block having a $3.175 \pm 0.125 \mathrm{~mm}$ radius bearing parallel to the midway. The loss on ignition of the developed samples was found by taking 5 to 10 grams of sample in a silica crucible kept in a muffle furnace at $800{ }^{\circ} \mathrm{C}$ for two hours. The uncured resins contents were determined using acetone extraction in a Soxhlet apparatus. The heat swell of the samples was determined by cutting the liner to a dimension of $10 \mathrm{~mm} \times 10 \mathrm{~mm} \times 4 \mathrm{~mm}$ at room temperature. The sample was held at $200 \pm 3{ }^{\circ} \mathrm{C}$ for about 40 minutes in a hot air oven. The water swell was determined by cutting a sample from the developed friction composite to a size of $50 \mathrm{~mm} \times 25 \mathrm{~mm}$ and soaking it fully in water at room temperature for 30 minutes. The difference in thickness was noted. These tests were conducted as per IS2742 Part 3 standards. The porosity was measured as per JIS D 4418 standards. Thermal conductivity was measured using a laser flash apparatus as per ASTM-E1461 Part-01 standards. The chase test following IS 2742 Part 4 standards was conducted to determine instantaneous friction and wear loss. The detailed procedure can be found in the study by Thiyagarajan et al. [7].

\subsection{Torque, brake factor, and wear measurements for the developed friction composites using an inertia brake dynamometer}

The braking performance of the developed friction composites was measured using a single end inertia brake dynamometer as per IS 11852-Part 3 standards (customized schedule). The dynamometer can simulate from 1 to $1,570 \mathrm{~kg} / \mathrm{m}^{2}$ by manually engaging or disengaging eight different inertia wheels. It is powered by a $175 \mathrm{~kW}$ capacity D.C motor controlled by a Kirloskar ${ }^{\circledR}$ variable frequency drive. The NI-6008® card acquires various data signals from temperature sensors, speed sensors, pressure sensors, and torque measurement, which are stored in a Labview ${ }^{\circledR}$ based system. The Labview ${ }^{\circledR}$ software-based control system can be loaded with various test schedules prepared according to JASO, FMVSS, AK Master, ECE R90, or any other customized test schedule. Three samples were tested, and consistent results were reported, with a $5 \%$ allowable error considered. The customized schedule rather than the normal schedule was followed to get an overview of performance in various working conditions (environments) based on specific vehicle parameters. The dynamometer specifications include: initial gross vehicle weight of $7.5 \mathrm{~kg} / \mathrm{m}^{2}$, rolling radius of $0.340 \mathrm{~m}$, effective radius of $0.139 \mathrm{~m}$, and liner thickness of $6.2 \mathrm{~mm}$. The drum diameter is $279 \mathrm{~mm}$, and other specifications of the drum are as per our previous study [7]. Brake factor is defined as the ratio of drum drag to the shoe tip effectiveness. Drum drag is defined as the ratio of the brake torque to the effective radius of the drum. Shoe tip effectiveness is defined as the product of input pressure and the effective area of the wheel cylinder. The brake factor was determined using equations given in Appendix II (a). The torque output was recorded using a data acquisition system that is calibrated through process variable equipment: pressure sensors, output temperature sensors (K-type thermocouples), speed sensors (encoders), and torque measurement (load cell) as per National Traceability Standards by NABL certified laboratories to maintain accuracy of the results. A schematic representation and photographic view of the dynamometer are presented in Fig. 3.
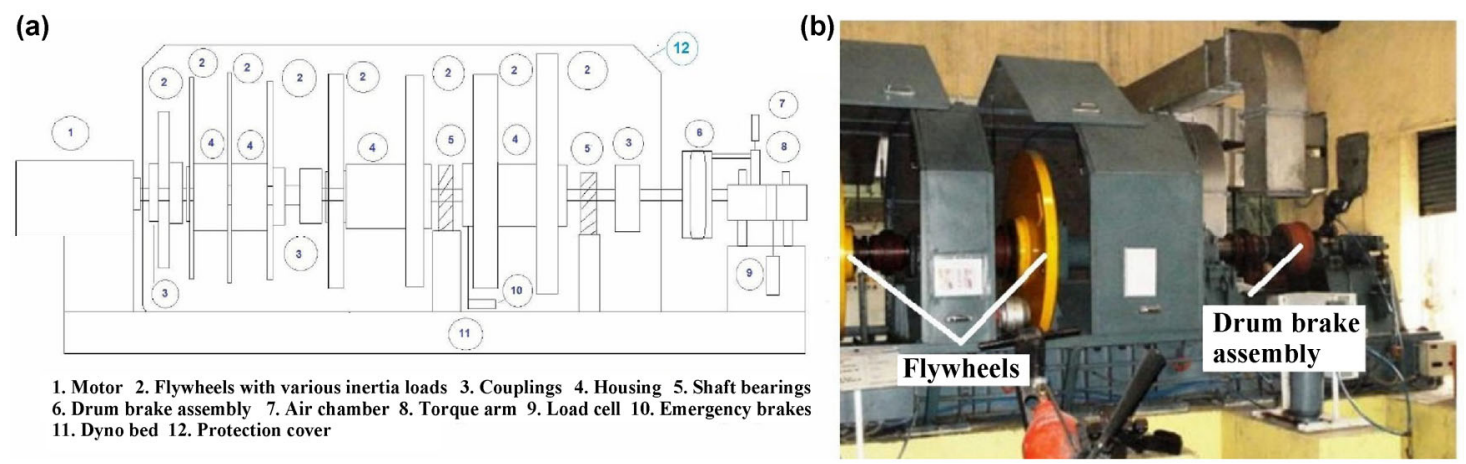

Fig. 3 Single end inertia brake dynamometer (a) schematic view and (b) photographic view. 
The pre-burnish check was done to ensure the friction composite surface was free from asperities present after grinding during its manufacture. Unbedded performance was done for the friction composite, to check whether the material performance is within the desired limits, well before bedding, as the friction composite had to work on the road, once it was fitted to the vehicle. Fade is defined as deterioration of frictional properties with increase in temperature, and the regaining of its original properties upon cooling is known as recovery. The fade test was done by repeating the braking action and increasing the temperature before starting the test procedure. Recovery was achieved by passing forced air through the blower to the mating interface. Because the friction composites must perform in wet environments in addition to dry environments, a water recovery test was also performed.

The brake jamming test was carried out to test the performance of the friction composites in early morning condition. Furthermore, the friction composite ought to be checked for wear at the end of high temperature. Therefore, a wear measurement was also performed at a higher temperature, though the fade test was done for such a case. But the fade test was followed by recovery so that it was impossible to measure the wear loss of the sample. Also, the temperature cannot be raised to such a level before the recovery test because effective contact would be established and the friction composite would be stable in friction and wear characteristics. The liner and drum thickness were measured after the bedding performance and high wear performance tests. The test procedure and its parameters are given in detail in Table 2.

The pressure fade and speed fade percentages are calculated based on formula (1):

$$
\begin{aligned}
& \text { Pressure fade } \% \text { or speed fade } \%= \\
& \frac{\text { max value }- \text { min value }}{\text { max value }} \times 100
\end{aligned}
$$

Pressure fade is calculated using the maximum and minimum brake factor values obtained from the set of pressures applied. Similarly, for speed fade, it is calculated from the maximum and minimum values obtained from the set of speeds. The thermal stress distribution at the developed friction composite

\begin{tabular}{|c|c|c|}
\hline S/No. & Test procedure & Parameter \\
\hline 1.0 & Pre-burnish check & Speed: $50 \mathrm{kmph}$, pressure: 30 bar \\
\hline \multirow[t]{2}{*}{2.0} & Unbedded performance & $50 \mathrm{kmph}$ (60 bar) (Brake factor are noted) \\
\hline & & $100 \mathrm{kmph}$ (60 bar) (Brake factor are noted) \\
\hline 3.0 & Burnish & $50 \mathrm{kmph} 30$ bar, 50 brake applications to establish $85 \%$ contact \\
\hline 4.0 & Bedded performance & $\begin{array}{l}\text { For various pressure and speed (Brake factor are noted, pressure fade and speed fade are } \\
\text { also calculated) }\end{array}$ \\
\hline \multirow[t]{2}{*}{5.0} & Fade \& recovery & $\begin{array}{l}\text { Flywheel speed: } 72 \text { to } 36 \mathrm{kmph} \text {, pressure: } 30 \text { bar, braking time: } 55 \text { seconds, No. of cycles: } 15 \\
\text { Hot stop test is done for one stop as per the previous performance test }\end{array}$ \\
\hline & & $\begin{array}{l}\text { Recovery: fan cooling is done; all the other conditions are same as for the fade test, except } \\
\text { that the braking time is increased to enable cooling } \\
\text { (Percentage fade \& recovery, brake factor, and lining temperature are measured) }\end{array}$ \\
\hline 6.0 & $\begin{array}{l}\text { Brake jamming and } \\
\text { water recovery }\end{array}$ & $\begin{array}{l}\text { Brake jamming test: braking speed: } 100 \text { to } 0 \mathrm{rpm} \text {, brake pressure: } 25 \mathrm{bar} \text {, temperature: } \\
40-45^{\circ} \mathrm{C}, 10 \text { brake applications } \\
\text { Wet recovery test } \\
\text { Baseline: test speed: } 40 \mathrm{kmph} \text {, temperature } 70-100{ }^{\circ} \mathrm{C} \text {, braking deceleration } 2.5 \mathrm{~m} / \mathrm{s}^{2} \text {, No. } \\
\text { of stops: } 3 \text {, interval: } 540 \mathrm{~seconds} \\
\text { Brake wetting: test speed: } 5 \text { to } 7 \mathrm{kmph} \text {, wetting time: } 2 \text { minutes } \\
\text { Recovery stops: test speed: } 40 \mathrm{kmph} \text {, deceleration: } 2.5 \mathrm{~m} / \mathrm{s}^{2} \text {, No. of stops: } 15 \text {, interval } \\
\text { between brakes: } 60 \text { seconds }\end{array}$ \\
\hline 7.0 & High wear performance & $\begin{array}{l}\text { Brake initial speed to final speed: } 420 \text { to } 210 \mathrm{rpm} \\
\text { Air braking pressure: } 2 \text { bar } \\
\text { Temperature before each brake application: } 200{ }^{\circ} \mathrm{C} \text {, cooling fan: off, No. of applications per } \\
\text { speed range: } 250\end{array}$ \\
\hline
\end{tabular}

Table 2 Test procedure of the full-scale inertia brake dynamometer (customized schedule). 
mating interface during maximum temperature rise was analyzed using Finite element analysis software (ANSYS). The analysis was performed using ANSYS R 15.0 software in which a three-dimensional (3D) rendering of the developed friction composite model was drawn using CREO. It was imported in Initial Graphics Exchange Specification (IGES) format to the analysis software. The parametric details were chosen based on the characterization results given in Table 3 and a Poison's ratio of 0.3. And the ambient temperature (lower limit temperature) considered was $35{ }^{\circ} \mathrm{C}$. Output torque and brake factors were only reported for the drum brake liner because the output torque would be more than the input torque; because the two liners' leading and trailing sides are actuated against the drum and thus the value would be high. The coefficient of friction has a profound effect on the brake factor, particularly for a leading shoe. To calculate the coefficient of friction value, the plot provided by Day [9] was used, as shown in Appendix II (b).

Table 3 Test results of various characteristics of the developed composites.

\begin{tabular}{|c|c|c|c|c|c|}
\hline \multirow{2}{*}{ S/No. } & \multirow{2}{*}{ Property } & \multirow{2}{*}{ Unit } & \multirow{2}{*}{$\begin{array}{c}\text { Test } \\
\text { standard }\end{array}$} & \multicolumn{2}{|c|}{ Observed value } \\
\hline & & & & FM01 & FM02 \\
\hline 1 & Specific gravity & No Unit & \multirow{7}{*}{$\begin{array}{l}\text { IS: } 2742 \\
\text { Part-3 }\end{array}$} & 1.90 & 1.88 \\
\hline 2 & Hardness & "L" Scale & & $89-100$ & $85-100$ \\
\hline 3 & $\begin{array}{l}\text { Cross breaking } \\
\text { strength }\end{array}$ & $\mathrm{MPa}$ & & 34.3 & 31.4 \\
\hline 4 & $\begin{array}{l}\text { Loss on ignition } \\
\text { at } 800{ }^{\circ} \mathrm{C}\end{array}$ & $\%$ & & 43.85 & 43.92 \\
\hline 5 & $\begin{array}{l}\text { Acetone } \\
\text { extraction }\end{array}$ & $\%$ & & 1.63 & 1.64 \\
\hline 6 & $\begin{array}{l}\text { Heat swell at } \\
200{ }^{\circ} \mathrm{C}\end{array}$ & $\mathrm{mm}$ & & 0.06 & 0.05 \\
\hline 7 & $\begin{array}{l}\text { Water swell } \\
\text { at room } \\
\text { temperature }\end{array}$ & $\mathrm{mm}$ & & Nil & Nil \\
\hline 8 & Porosity & $\%$ & JIS D 4418 & 4.8 & 5.2 \\
\hline 9 & $\begin{array}{l}\text { Thermal } \\
\text { conductivity }\end{array}$ & $\mathrm{W} / \mathrm{mK}$ & $\begin{array}{l}\text { ASTM-E- } \\
1461-01\end{array}$ & 2.10 & 1.99 \\
\hline \multirow[t]{3}{*}{10} & \multicolumn{2}{|c|}{ Coefficient of friction } & & & \\
\hline & i) Normal friction & $\mu$ & IS: 2742 & 0.469 & 0.467 \\
\hline & ii) Hot friction & $\mu$ & Part-4 & 0.468 & 0.427 \\
\hline \multirow[t]{3}{*}{11} & Wear & & & & \\
\hline & i) Weight loss & $\%$ & \multirow{2}{*}{$\begin{array}{l}\text { IS: } 2742 \\
\text { Part-4 }\end{array}$} & 3.3 & 2.5 \\
\hline & ii) Thickness loss & $\%$ & & 2.2 & 1.4 \\
\hline
\end{tabular}

The worn surfaces of the friction composites were characterized using a TESCAN VEGA 3LMU SEM machine of the Czech Republic which has a tungsten heated cathode electron gun. 3D surface profiles were obtained using a non-contact type white light interferometer.

\subsection{Corrosion behavior of the developed friction composites}

The developed friction composites were tested for corrosion behavior in four different environments: normal water treatment, $\mathrm{NaCl}$ solution treatment, brake oil environment, and a humidity chamber. In normal water environment, the samples were tested in a water environment maintained at room temperature (kept untouched) for 72 hours. In $\mathrm{NaCl}$ solution environment, the samples were tested (in $5 \% \mathrm{NaCl}$ ) for 72 hours under room temperature conditions. For the above tests, the $\mathrm{pH}$ was noted before and after the test using litmus paper and the samples were visualized intermittently for 24 and 48 hours. In the case of the brake oil environment, the samples were tested in dot-3 brake oil for 72 hours under room temperature conditions. In humidity chamber testing, samples were placed in a humidity chamber for 72 hours temperature maintained at $40{ }^{\circ} \mathrm{C}$ with relative humidity 90\%-95\%. For all test samples above, the corrosion was reported using macro photos, roughness profile using a 3D white light interferometer, and weight loss before/after the test. The $\mathrm{pH}$ was also measured for the solution before, after, and intermediate of the test to confirm that the corrosion effect was only due to the material and not due to the solution effect.

\section{Results and discussion}

\subsection{Physical, chemical, mechanical, and thermal characterizations of the developed friction composites}

The test results of physical, chemical, mechanical, and thermal characterizations of the developed friction composites carried out as per the industrial standards are given in Table 3.

The specific gravity, hardness, and cross breaking strength of the FM01 are higher than that of the FM02 due to the presence of highly dense steel fibers which 
possess slightly higher carbon content than stainless steel and makes the composite harder and more brittle. The heat swell was also slightly higher for the FM01 due to the highly conductive steel fibers. This property also contributes to better curing of composites as inferred from a reduction in the acetone extraction value. Loss on ignition value is slightly less for the FM01, due to the presence of a higher percentage of iron and carbon content in steel fibers (as shown in Table 1) that are highly resistant to thermal degradation [7]. The porosity of the FM02 is higher than that of the FM01, which is because stainless steel fibers have better size and good fiber shape, as shown in Table 1 and Fig. 1(b). It is a well-known fact that the higher the hardness, the lower the porosity, due to tighter compaction of the ingredients, as explained in Ref. [10]. The thermal conductivity of the FM01 was higher than that of the FM02 because the thermal conductivity of steel fiber is superior to that of stainless steel fiber [3, 7].

The normal and hot friction values of the FM01 are higher due to the more abrasive and heat stable nature of steel fibers, which enable high friction in both aspects [7]. The higher the friction, the higher the heat generation at the interface. This leads to the degradation of less stable ingredients, enabling more weight and thickness loss in the FM01.

\subsection{Tribological characterizations of the developed friction composites}

\subsubsection{Unbedded and bedded performance}

Unbedded performance plays a vital role when the newly manufactured brake friction composite is fitted to the vehicle. A stable coefficient of friction (the brake factor in this study) with lower wear rate is the prime requirement for the friction material, and this is essential throughout its service life. The FM02 stainless steel-based friction composites showed better performance results in the unbedded performance because stainless steel fibers were present at the interface, and these possess good fiber characteristics as inferred in previous sections. Before bedding, the real fibers come in contact with the mating surface. In Fig. 4, the FM01 composites showed more undulations in the plot, which could be due to the hard steel fibers coming in contact with the mating surface, and due to its severe

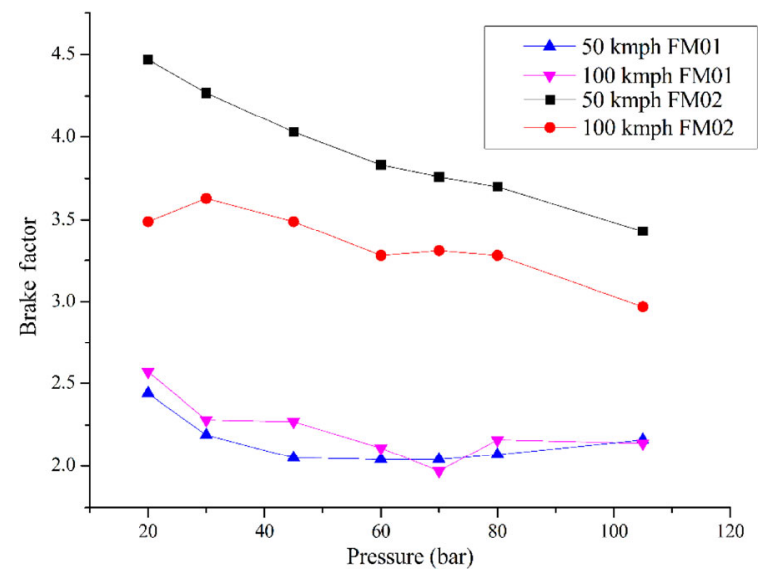

Fig. 4 Unbedded performance of developed friction composites.

abrasion action over the mating surface there are more variations in the brake factor. This higher abrasive nature of steel fibers is due to its higher carbon content, leading to microstructural changes that cause higher levels of hardness. It is stated in the literature that the fluctuations in the plot are due to the mismatch with Amonton's law. The law states that friction is independent of the contact area. But in the case of polymeric based friction composites, it is inapplicable because it is made up of versatile ingredients which influence friction by making contact with the mating surface $[2,11]$.

\subsubsection{Bedded performance}

Bedded performance of the friction materials is studied upon the establishment of 80 percent contact with the mating surface. It includes several applications to study the performance behavior of the friction materials. The pressure and speed play a crucial role in determining the friction (brake factor in this study) and wear characteristics. In the pressure-speed study, the brake factor decreases with increase in pressure, and low undulations in the curve are essential for improved performance. A similar trend can be seen in the FM01 composites in Fig. 5(a), but the FM02 composites, as shown in Fig. 5(b), produced more undulations in the curve. It is due to the exposure of stainless steel fiber to the mating surface, leading to abrasion and causing a change in brake factor value. Though brake undulations were present, the brake factor was maintained at the desired level to meet the vehicle braking criterion. This result is similar to the findings of Fu et al. [12]. In this study, the brake factor value is higher in the 
case of the FM02, as shown in Fig. 5(b), compared to the FM01 as observed in Fig. 5(a). The feasible reasons for such an increase in values are as follows: the friction levels increase with metal fiber content and also depending upon the strength, size, shape, and nature of the metallic ingredients, as observed in this study, which is in tandem with Ref. [13]. Stainless steel fibers, which possess ferrite with distributed carbide structure helped to increase the friction by interacting with the counterpart by its exposure. A similar trend was seen in Ref. [12]. Another factor could be that when the metal particles/fibers get worn out and entrapped in the interface, they evenly cause the friction boosting [14]. The reduction in brake factor is due to the irregular shapes of the steel fibers, forming peak asperities and it gets sheared up leading to the reduction in friction. Though steel fibers-based friction composites possess high hardness, it could not produce higher friction (brake factor) value that could be due to polymeric ingredients degradation which is explained in forthcoming sections. A similar trend was seen in the literature, though the hardness is higher for the mullite fiber-based friction material than for the steel fiber-based friction composites, the friction value is lower for mullite [15]. The higher friction value of FM02 is also due to the higher porosity as stated by Thiyagarajan et al. [7], by Jaafar et al. [10] since it enhances better heat dissipation leading to enhanced results. This study shows that with lower speed and higher pressure, FM02 has good friction behavior which could reduce the noise in accordance with Refs. $[5,16]$. The pressure fade percentage is given in Fig. 5(c), in which the FM01 showed better performance results by producing lesser fade due to the better strength of the steel fibers. In the case of the speed fade as shown in Fig. 5(d), the FM02 showed lesser fade percentage when compared to the FM01. There are fluctuations in the values witnessed in Figs. 5(c) and 5(d) for both composites. These graphs were plotted by considering the higher and lower values of the bedded performance based on the respective speeds and pressure. Upon the change in pressure with speed, the curve increases leading to an increase in the output torque as shown in Fig. 5(e). The decrease in value with an increase in pressure and speed could be due to the real contact of the ingredients with the mating surface which could sometimes enhance friction, i.e., when fibers are in contact with mating, it can also decrease friction when there is more degradation of polymeric ingredients at the interface leading to visco-elasticity of polymeric materials and liberation of carbon dioxide. But in the case of the brake factor, it is also dependent on the input (applied force) which varies. Thus, there is a deviation in value. These are also seen in Refs. [12, 14, 17, 18]. These broader fluctuations in friction can cause the unstable behavior of the friction films at the interface subjected to mechano-chemical and surface energy interactions, which varies with the composition nature and metallic ingredients nature used [19].

In this study, there is an increase in brake factor with lower speeds in the case of FM02 composites due to the better contact of stainless steel fiber with the mating surface. But in the case of higher speed, it is quite the opposite, where the brake factor decreases drastically for both the composites. A similar trend was described by Blau and McLaughlin [20] where friction materials are near to the fade region leading to the local flash temperature, which is higher than the bulk temperature of the material leading to the softening of pad material and a decrease in shear strength. It is also very clear from the frictional heating theory that when the speed increases, an increase in temperature of the interface is observed [20] which impacts the friction level.

\subsubsection{Fade and recovery behavior}

Fade plays a crucial role in friction performance of the material. In this present study, the FM01 composite produced enhanced results compared to the FM02. This increase in brake factors is mainly due to the following reasons. The tribological performance of the friction materials is dependent on adhesion, deformation of the materials as well as working temperature conditions. It is essential that the friction materials should have optimal thermal conductivity because when the thermal conductivity is higher, it has a negative impact on the brake fluid, and when the thermal conductivity is lower, it leads to the degradation of the organic ingredients. In the present work, the steel fibers possess higher thermal conductivity compared to the stainless steel fibers [3, 7], which leads to the dissipation of heat through the materials. This, in turn, increases the temperature in 

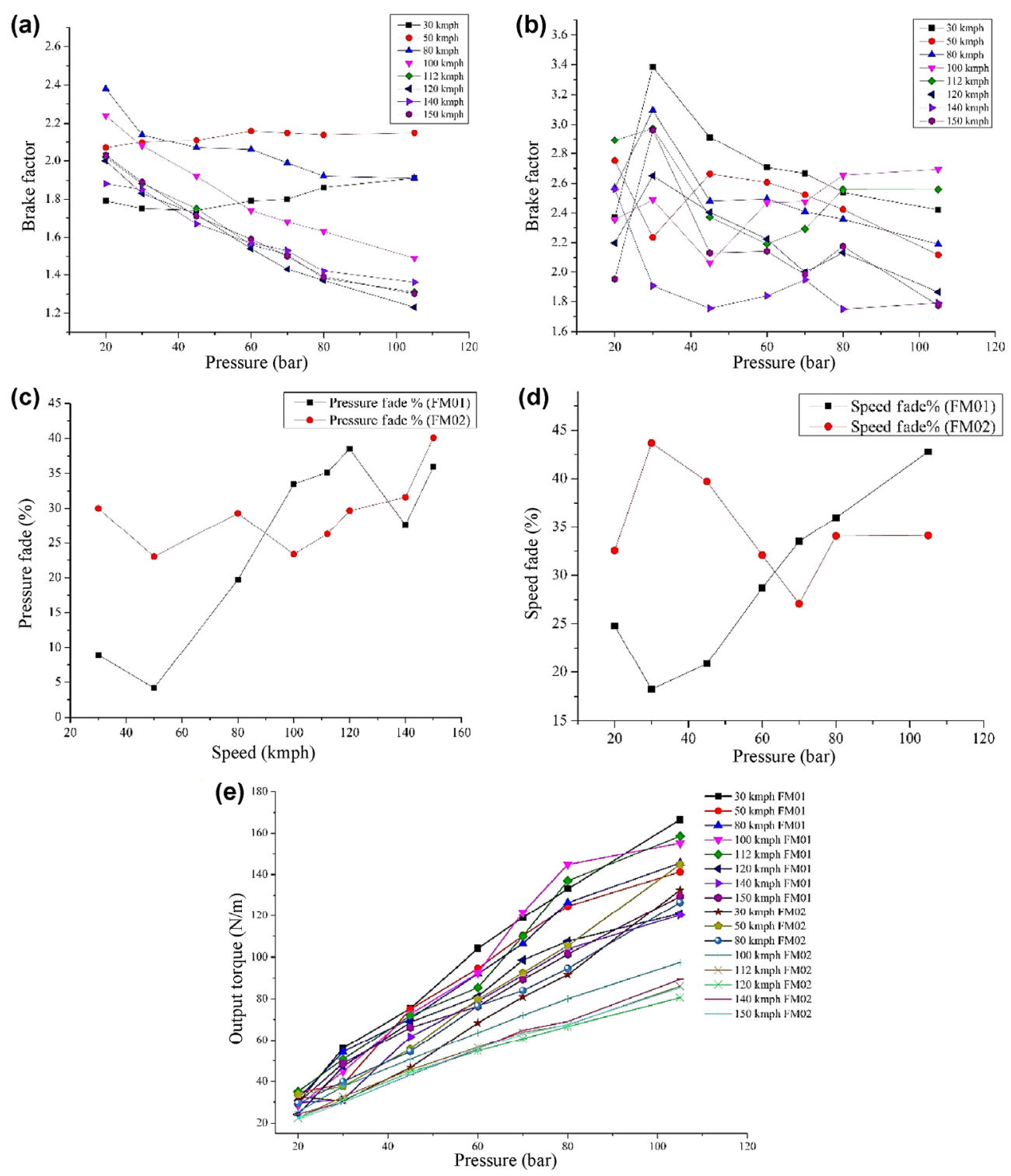

Fig. 5 (a) Bedded performance of the FM01 composite, (b) bedded performance of the FM02 composite, (c) pressure fade \% of tested composites, (d) speed fade \% of tested composites, and (e) output torque of bedded performance for FM01 and FM02 composites.

the liner as well as the interface. Also, the abrasive nature of the steel fiber which is used may increase the temperature at the interface. Another important reason for the increase in friction value of the FM01 is due to the higher temperature strength of the steel fibers due to the presence of higher carbon content which creates microstructural changes by forming ferrite with pearlite structure. This makes the steel fibers to withstand such high temperature. The percentage fade of the FM01 is $-0.8 \%$, which denotes the negative fade, and the same is reported by Park et al. [5]. Highly negative fade leads to an increase in stick-slip phenomenon behavior. This is caused when static friction is more than the dynamic friction, attributing to the highest adhesion of steel fibers with the mating surface. The percentage fade of FM02 is $24.1 \%$, though it is somewhat high compared to the FM01; the positive fade is always acceptable since negative fade will cause squeal. So, the positive fade does not cause such problems like squeal noise as observed by others [5, 14]. Another factor was the porosity, and if it is a higher value, lesser is the squeal. This also infers that the FM02 will reduce the squeal [21]. The study of noise squeal for the composites is the near future scope of this study. It is known that the absorption of heat and energy are 
prominent for higher porosity, which could lead to positive fade. It is visualized in Fig. 6(b), more undulations in the graph which are mainly due to the stainless steel fibers which get exposed during the cycle and another reason would be due to the abrasive wear of the worn surface particles from the mating surface which trap between the interface and cause such changes. These types of undulations are also seen in Ref. [12]. Due to the abrasive action of steel fibers leading to higher friction of steel fiberbased friction composite compared to the stainless steel fiber-based friction composites. Thus, there is an increase in temperature in the drum as well as the liner. Another aspect is that even if the thermal conductivity is high if effusivity is less then there will be an increase in temperature. Similarly, the effusivity of the FM01 (2.127 $\left.\mathrm{Jm}^{-2} \mathrm{~K}^{-1} \mathrm{~s}^{-1 / 2}\right)$ is less compared to FM02 (2.164 $\left.\mathrm{Jm}^{-2} \mathrm{~K}^{-1} \mathrm{~s}^{-1 / 2}\right)$. This is in accordance with the findings of Kumar and Bijwe [18]. So, the FM01 has a high temperature which is 1.1 times in the case of the liner, while it is 1.02 times for drum than the
FM02. This is the type of higher temperature rise behavior is also seen in the findings of Jang et al. [4] and Kumar and Bijwe [18]. The fade and recovery behaviors with liner and drum temperature rise of the FM01 and the FM02 are shown in Figs. 6(a) and 6(b), while fade and recovery rate percentage observed with a maximum rise in drum and liner temperatures are given in Fig. 6(c).

Recovery is an important phenomenon for regaining the desired friction parameters upon cooling. Due to the cooling of the braking surface, the friction film formation contributing abrasive mechanism (third body abrasion leading to rolling abrasion) and reduced deformation of films by its composition are responsible for the difference in fade and recovery behavior [11]. As seen in Fig. 6(b), the recovery curve increases in case of FM02 composites which was mainly due to the porosity, because it helps to increase the friction value by enabling cooling during braking as stated in Ref. [10]. There are some changes (ups and down), i.e., a decrease in coefficient of friction for some range with

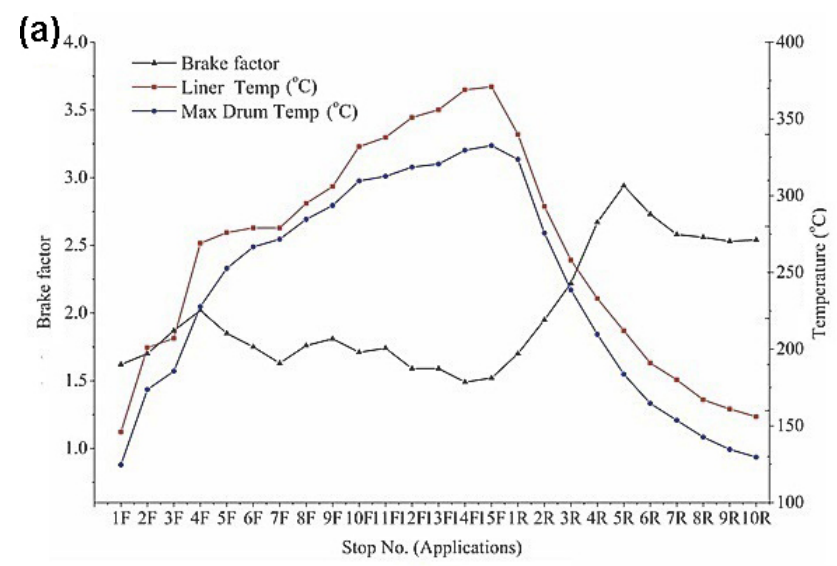

(b)

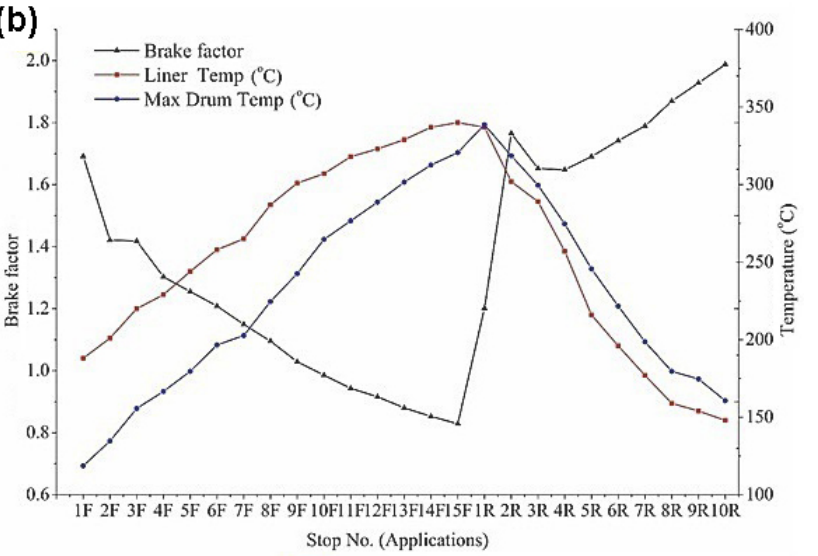

(c)

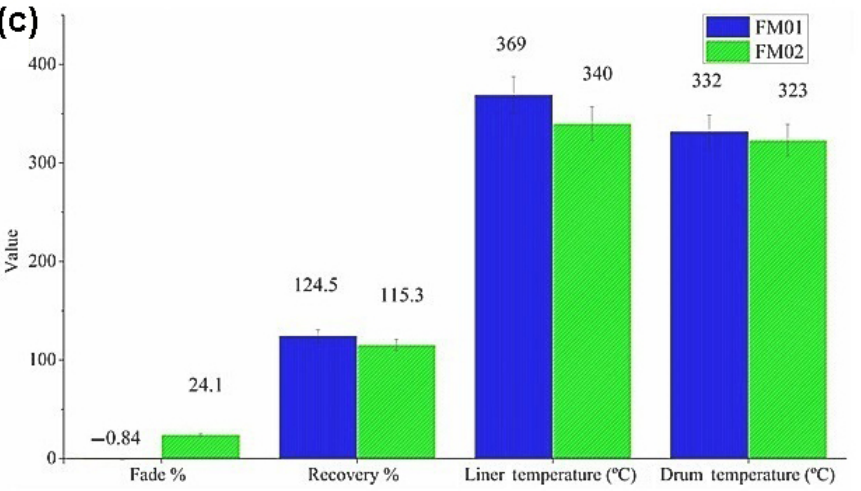

Fig. 6 (a) Fade, recovery, liner, and drum temperatures of the FM01 composite, (b) fade, recovery, liner and drum temperatures of the FM02 composite, and (c) fade and recovery percentage with the maximum rise in drum and liner temperatures of tested friction composites. 
a decrease in temperature in case of both friction composites FM-01 and FM-02 as shown in Figs. 6(a) and 6(b) which are mainly due to the change in the rheology between the surface layer and wear debris as reported by Ji et al. [22]. The composites which recover well after fade cycles are considered to be beneficial, in the case of the FM01, which shows slightly higher recovery due to the abrasive nature of the steel fiber compared to the stainless steel fiber that could have formed more third bodies enabling such increase in value. A similar trend was observed by Bijwe and Kumar [3].

The developed model was subjected to hexahedron meshing which showed 83676 Nodes and 14996 elements. Then the model developed was subjected to an equivalent stress condition with maximum liner temperature based on data obtained from Fig.6(c) was fed as input (upper limit temperature). Based on the thermal stress distribution of the friction composites as shown in Figs. 7(a) and 7(b), the maximum and minimum stresses developed on the composites FM01 are 5.619102 and $1.871234 \mathrm{MPa}$, while FM02 composites showed $4.255294 \mathrm{MPa}$, and $1.309044 \mathrm{MPa}$ respectively. From Figs. 7(a) and 7(b), it is also seen that maximum stress was found on the sides which are due to the reduced mating contact with the drum which may be due to a reduction in contact area [23].

The decreased stress development in FM02 composites is very beneficial since increased thermal stress causes enhanced failure of the composites. Also, the key factor for this reduced thermal stress is due to the less aggressive nature of the composite to the mating surface leading to the lesser temperature rise in the composites that was fed as an input factor.

\subsubsection{Brake jamming and wet recovery}

Brake jamming test is mainly to measure the morning sharpness of the friction material. The FM02 composite produced better results than the FM01 as shown in Fig. 8, which is mainly due to the chromium content in its chemical constituents that causes a protection layer which prevents the vulnerability to corrosion. The steel fibers when exposed to water spray, it starts corroding thus forming an oxide film on the surface of the composite, and the detailed study on corrosion is done in forthcoming sections. The oxide film formed acts as a lubricant thereby leading to reduced friction, which requires the driver to press the brake very hard. This is a very problematic situation because the driver needs the same level of comfort throughout the braking material's lifespan, this inconvenient situation may also lead to an increase in stopping distance, which could also constitute the scope of future work. Another important fact is that in the case of brake jamming, only water is sprayed on the surface, so upon braking, it gets dried up. However, it is in the range of dry friction alone, because it is a common postulate that water decreases the temperature at the interface and also forms a hydrodynamic film at the interface [24]. But it is seen that within this speed range, the pressure developed by the water is not able to withstand the load, thereby leading to an increase in friction by solid-solid contacts [25].

In the case of water recovery, the composites are dipped in the water for 2 minutes. Initially, the brake factor is lesser, then it gets increased to an extent, (a)

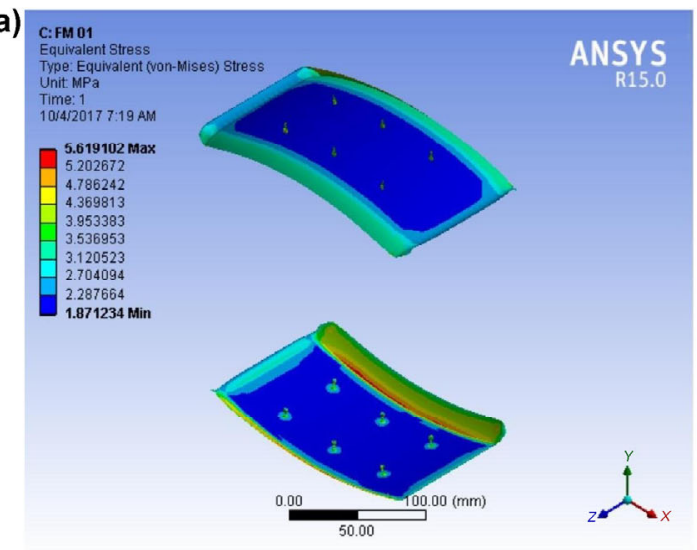

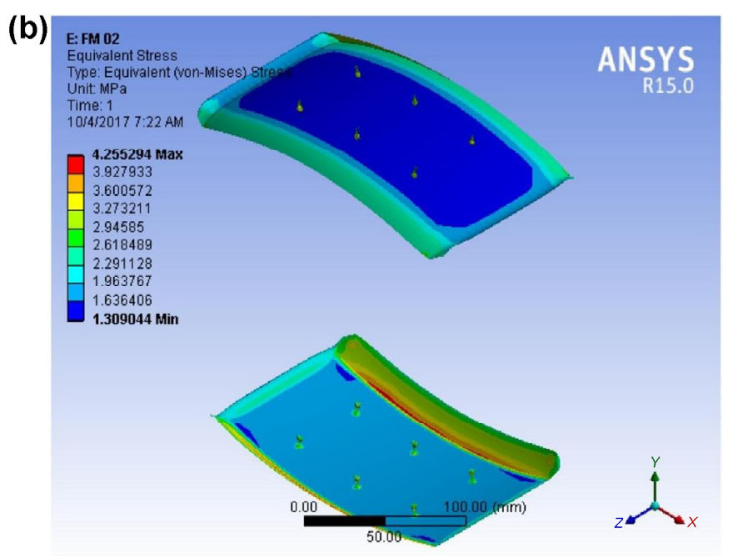

Fig. 7 Thermal stress distribution of the developed composite during maximum temperature rise for (a) FM01 and (b) FM02. 
after which it gets deteriorated as shown in Fig. 9. A similar trend is also reported by Blau et al. [20, 26]. This increase in friction value (brake factor) is mainly due to the metallic ingredients, which gets in contact with the mating surface thereby leading to increase in sound noise [27]. The effect of sound noise during dry and wet conditions of braking is the scope for future study. It is also stated in Martens-Stribeck theory that the friction should reduce, as it enters mixed and elastohydrodynamic regions. But the behavior of friction material is quite complicated in wet conditions due to the influence of water, mechanical and thermal stress [28]. The brake factor obtained for both the composites had slight variations which may occur due to the hard fiber exposure at the contact interface with the drum.

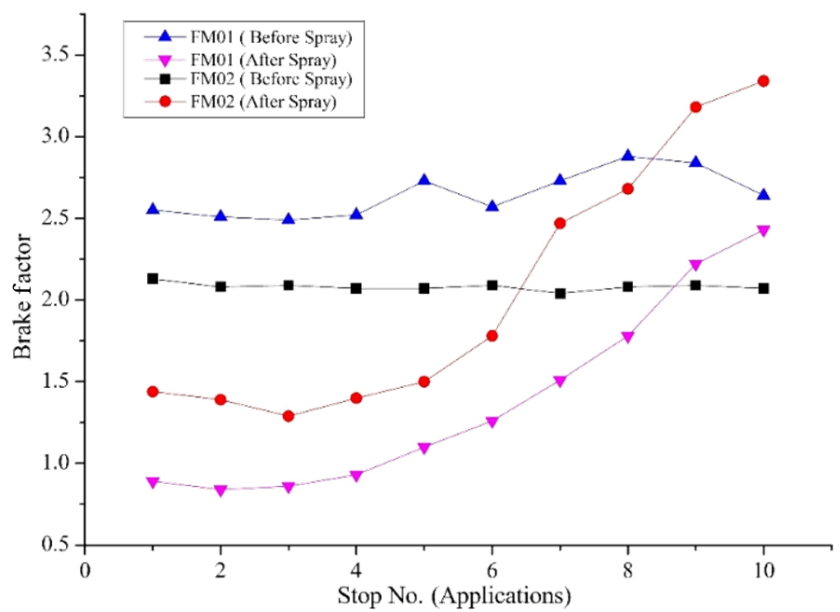

Fig. 8 Brake jamming test performance of the developed composites.

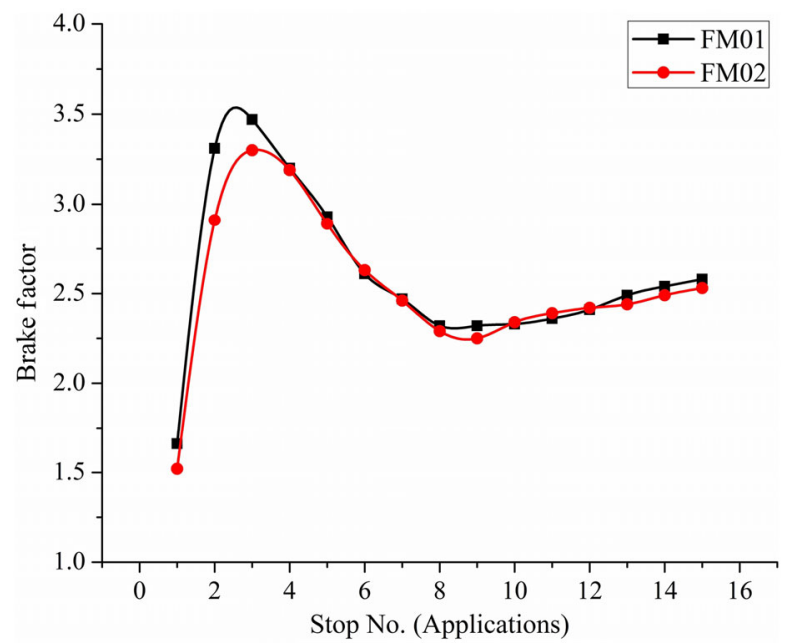

Fig. 9 Wet recovery performance of developed composites.

\subsubsection{Wear performance}

Wear is a complex phenomenon in the friction composites that possesses many mechanisms namely abrasive, adhesive, and oxidation, etc. The wear loss of the composites upon various testing conditions and its drum wear are shown in Fig. 10. It is postulated that commonly friction (brake factor in this study) and wear do not correlate in most of the cases; higher the friction, higher the wear will be [6]. Similarly, FM01 composites produced more wear compared to the FM02. The possible reasons for such behavior are discussed below. The steel fiber being hard and abrasive due to the presence of higher carbon content than stainless steel increased the friction level in the friction composites and created higher heat generation and temperature rise at the braking interface that enables the degradation of polymeric ingredients leading to material debonding thus increase in wear rate. Another possible reason could be the higher interface temperature in FM01 that causes the severe plastic deformation at the interface leading to the production of coarse cast iron particles and leading to abrasive wear [29]. These large iron oxides are formed in the loose wear particles, leading to the suggestion that tribo-oxidation not only occurs in steel fibers but also in cast iron surface which leads to the major wear mechanism as stated in Ref. [30] and the formation of such particles is confirmed using elemental mapping in Fig. 12. The porosity also plays a vital role in the removal of heat from the pad surface, which also leads to a better wear resistance [7]. This higher porosity helps in preventing the degradation of polymeric ingredients as in the case of the FM02 composite. Another reason is that stainless steel fiber being less hard prevents the damage of the counter surface thereby producing good plateaus which act as a barrier by trapping the worn materials [31]. The drum loss is severe for the FM01 composites when compared to FM02. This is similar to the findings of Jang et al. [4], where the steel fiber creates more rubbing surfaces causing large oscillations leading to higher wear, as observed in the previous works [3, 7]. The more wear of the mating surface is mainly due to the hard nature of the steel fibers that causes ploughing action on the counter surface. This hard behavior of the steel fiber is due to the increase in carbon content influencing its 

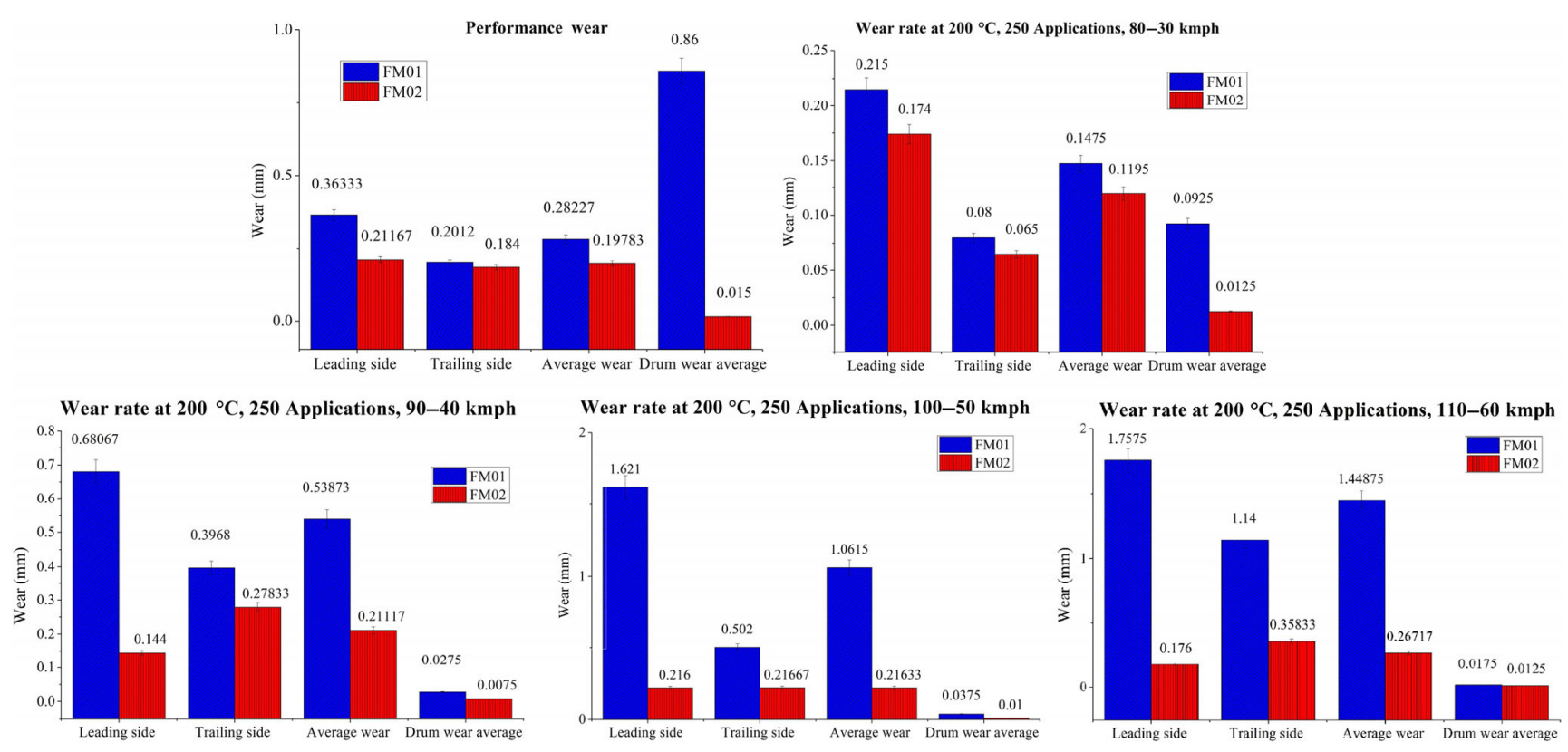

Fig. 10 Wear loss of the various conditions tested friction composites and its drum wear average.

microstructure. While the stainless steel fiber as stated above is less hard and doesn't cause such behavior. In Fig. 10, the leading edge has more wear compared to trailing edge due to more self-load of the drum.

\subsubsection{Worn surface characterizations}

Scanning Electron Microscopy (SEM) was very helpful in determining the characteristics of the worn surfaces. Friction films formation is one of the important criteria for tribological performance which will vary according to environmental conditions as well as material performance during braking. Generally, two types of films will be formed: one is loose granular film while the other is dense sheet film. The primary plateaus are formed by adhering fibers which play a key role in arresting the fine wear particles from movement at the interface; thus the loose granular films are formed. These loose fine wear particles which are the main constituents of polymeric ingredients, aramid, etc., stick together with an increase in pressure and temperature during braking, thus forming secondary plateaus [32] leading to dense film formations. It is stated that primary plateaus have a load-bearing capacity as well as boost friction, while the secondary plateaus deteriorate the same. So, it is always advisable to have more primary and less secondary plateaus $[3,6,11]$. The FM02 composite shows more primary plateaus which are seen as black patches in Fig. 11(a), with less secondary plateaus, compared to the FM01 composites as shown in Fig. 11(b). The sliding direction is also seen in both figures. It is also clearly visualized in Fig. 11(b) that the primary plateaus get nucleated leading to the reduction of friction properties. This is because dense films upon growing by the mating surface it forms loose granular films and the more rotor wear causes such induced nucleation. The size of the primary plateaus are analyzed using the image analysis technique [33] in which FM02 shows an average of $1.300012527 \mu \mathrm{m}$ size plateaus while the FM01 is $0.411437435 \mu \mathrm{m}$. The closure view of the samples tested in dynamometer showing plateaus formation is given in Figs. 11(c) and 11(d) for the FM02 and the FM01 respectively. Upon an increase in temperature, the polymeric and less stable ingredients get worn out and thus generate debris from the sliding surfaces fill between the friction materials or diffused to the mating surface [7]. This shows plateaus and the transfer film formation in Fig. 11(d).

The stability of the friction film plays an important role in good friction as in the case of the FM02, which shows stable friction film. This is visualized by the coverage of the sliding surface with patches. In the case of Fig. 11(e), the fibers are visible in the sliding direction [34]. It is visualized, since the abrasion mechanism has taken place between the friction materials and the mating surface, and it also shows 

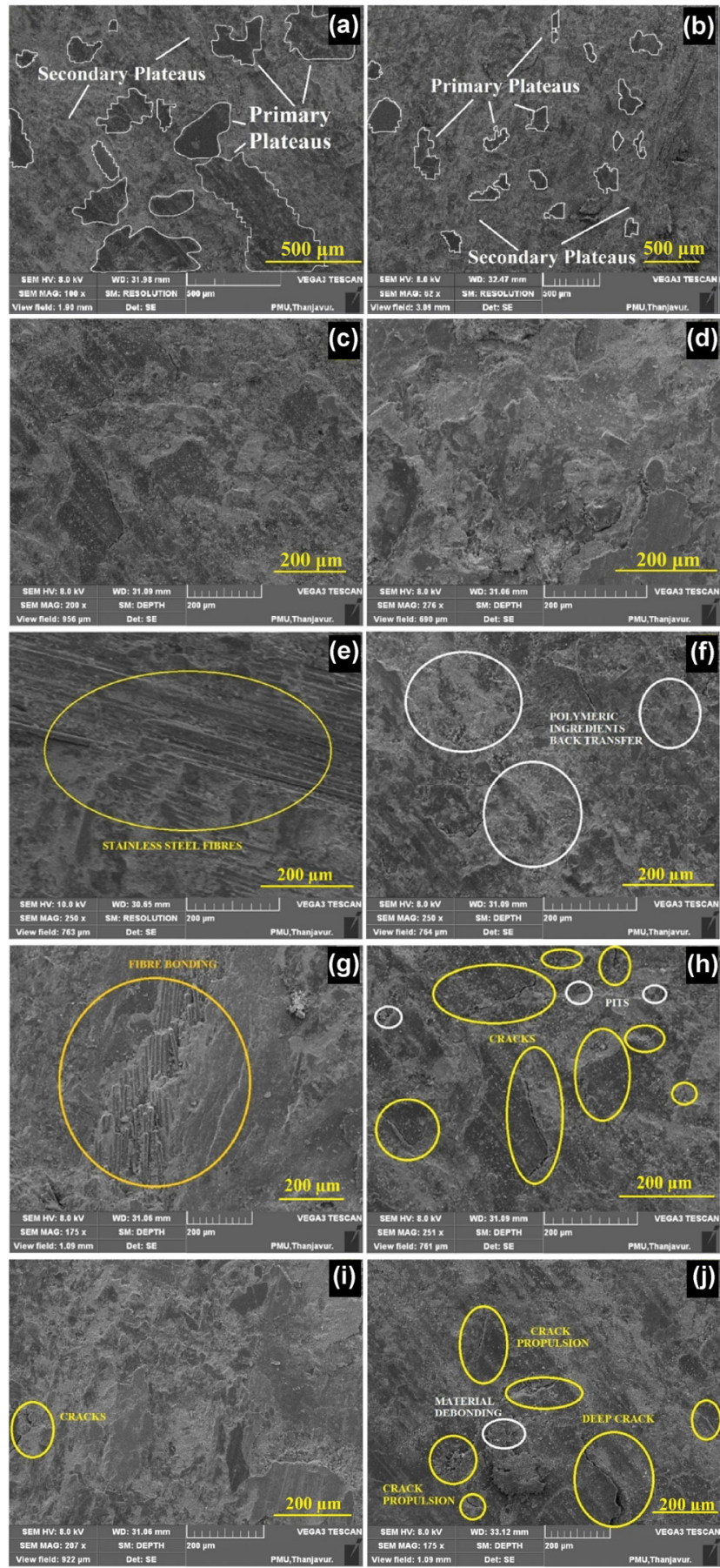

Fig. 11 SEM images of (a) plateaus formation of the FM02 dyno tested composites, (b) plateaus formation of the FM01 dyno tested composites, (c) plateaus formation of the FM02 dyno tested composites closure view, (d) plateaus formation of the FM01 dyno tested composites closure view, (e) fibers in the direction of sliding of the FM02 composite, (f) more back transfer of polymeric ingredients in the FM01 composite, (g) firm bonding of stainless steel fiber in the FM02 composite, (h) crack initialization and spalling pits of the FM01 composite, (i) less crack in the FM02 composite, and (j) deep crack propulsion and material debonding in the FM01 composite. the compacted fibers for the enhancement of friction value. There are more back transfer of less thermally stable ingredients on the surface of FM01, which deteriorate the friction behavior as visualized in Fig. 11(f).

The firm bonding of stainless fibers with matrix is shown in Fig. 11(g), which is due to the better adhesion property with the binder matrix [12]. There is more formation of spalling pits in Fig. 11(h), which is mainly due to the hard fibers that get broken by forming hard asperities. This leads to more abrasive wear and due to more interface temperature, and the formation of cracks [20]. In the case of Fig. 11(i), there are fewer cracks formed compared to the FM01 as shown in Fig. 11(j). The poor bonding between the steel fiber and the matrix also shows more crack propulsion, debonding, and fiber pull out upon exposure to braking cycles $[31,35,36]$.

To confirm the transfer of drum wear debris and plateau formation elemental mapping, Energy Dispersive X-ray analysis (EDAX) was performed on the worn surface of the developed composites. The worn surface of FM01 composites showed more secondary plateaus as explained in SEM Fig. 11(b) and also represented in Fig. 12(a) as ' 2 ', while the primary plateaus are denoted as ' 1 '. It is clear from the wear testing that FM01 showed more drum wear which causes more back transfer of Iron (Fe) and Manganese $(\mathrm{Mn})$, with oxide $(\mathrm{O})$ upon oxidation from drum made of cast iron to get transfer to the softer area (i.e., the secondary plateaus) as shown in Figs. 12(b), 12(c), and 12(f). This back transfer is mainly due to hightemperature rise caused by more abrasive nature of the steel fibers in the composite upon mating with the drum. To confirm that it's the back transfer of low thermal stable ingredients that causes secondary plateaus $\mathrm{C}$ and $\mathrm{O}$ (Figs. 12 (d) and 12(f)) mapping confirmed the same. A mapping study of Aranganathan and Bijwe [37], stated that the presence of $\mathrm{C}$ and $\mathrm{O}$ in the mapping of brake friction materials denotes resin and low thermal stable ingredients.

Even the presence of ' $S$ ' in Fig. 12(e) denotes the crumb rubber and sulfur that are present in the formulation in the secondary plateau region ' 2 '. Figure 12(g) denotes the EDAX spectrum of secondary plateau region which is further marked as ' 3 ' in Fig. 12(a). It is clear from the spectrum that more Fe, 


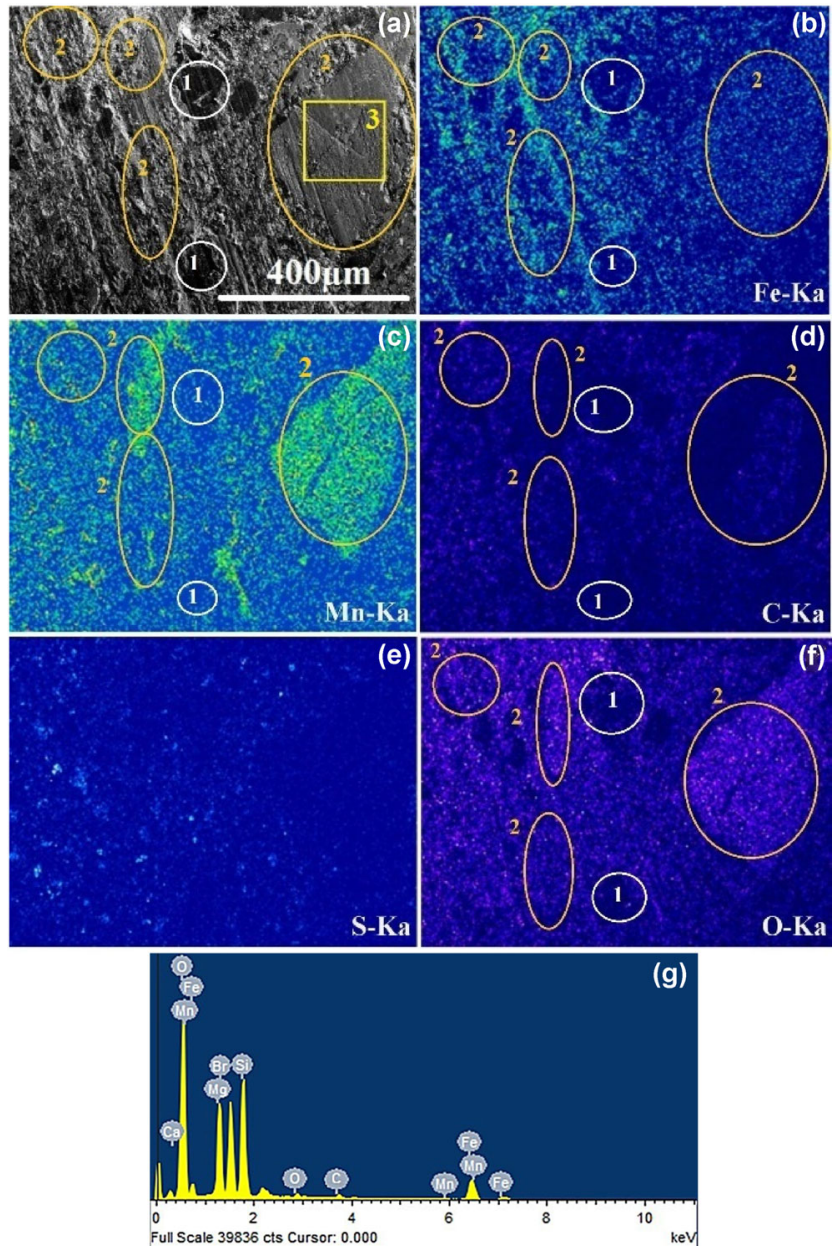

Fig. 12 Worn surfaces of the FM01 composites (a) electron image, with elemental mapping, (b)-(f) electron images with elemental mapping, and (g) EDAX spectra representing back transfer (secondary plateau formation).

$\mathrm{Mn}, \mathrm{C}$, and $\mathrm{O}$ are the back-transfer elements, smaller traces of $\mathrm{Mg}$, Si from vermiculite, and Ca from Calcium Carbonate. In the case of FM02 where the worn surface electron image is shown in Fig. 13(a) in which ' 1 ' denotes the primary plateaus which are more in number as shown in Fig. 11(a), ' 2 ' denotes the secondary plateaus which is lesser as compared to FM01.

To confirm the back-transfer rate from drum since FM02 composite was very less aggressive to drum, the elemental mapping Figs. 13(b), 13(c), and 13(f) showed less area coverage compared to FM01. While Figs. 13(d)-3(f) show the back transfer of the less stable ingredients like aramid, resin, and rubber, etc. To confirm the presence of rubber (secondary binders and additives) Fig. 13(e), elemental mapping of sulfur proved the same; even it is also seen in secondary plateau region ' 2 '. Also, the region denoted as ' 2 ' showed the presence of Fe and $\mathrm{Mn}$, with $\mathrm{C}$ and $\mathrm{O}$, because it is back transfer of less stable ingredients with drum wear debris. While the ' 1 ' denoted region showed much less content because it is merely the compaction of thermally stable ingredients. To find out the composition of primary plateaus, the EDAX was done for spectrum denoted as ' 3 ' in Fig. 13(a). The EDAX spectrum Fig. 13(g) shows Fe, O, C, and Mn which are also from the back transfer of drum wear debris which gets entrapped in the primary plateaus similar is confirmed with mapping except for $\mathrm{O}$ which is not present in it. Furthermore, while the $\mathrm{Cr}$ with $\mathrm{Fe}, \mathrm{C}, \mathrm{Mn}$, and $\mathrm{Mg}$ denotes the stainless steel fibers content which also possesses such ingredients in its chemical composition as shown in Table 1.

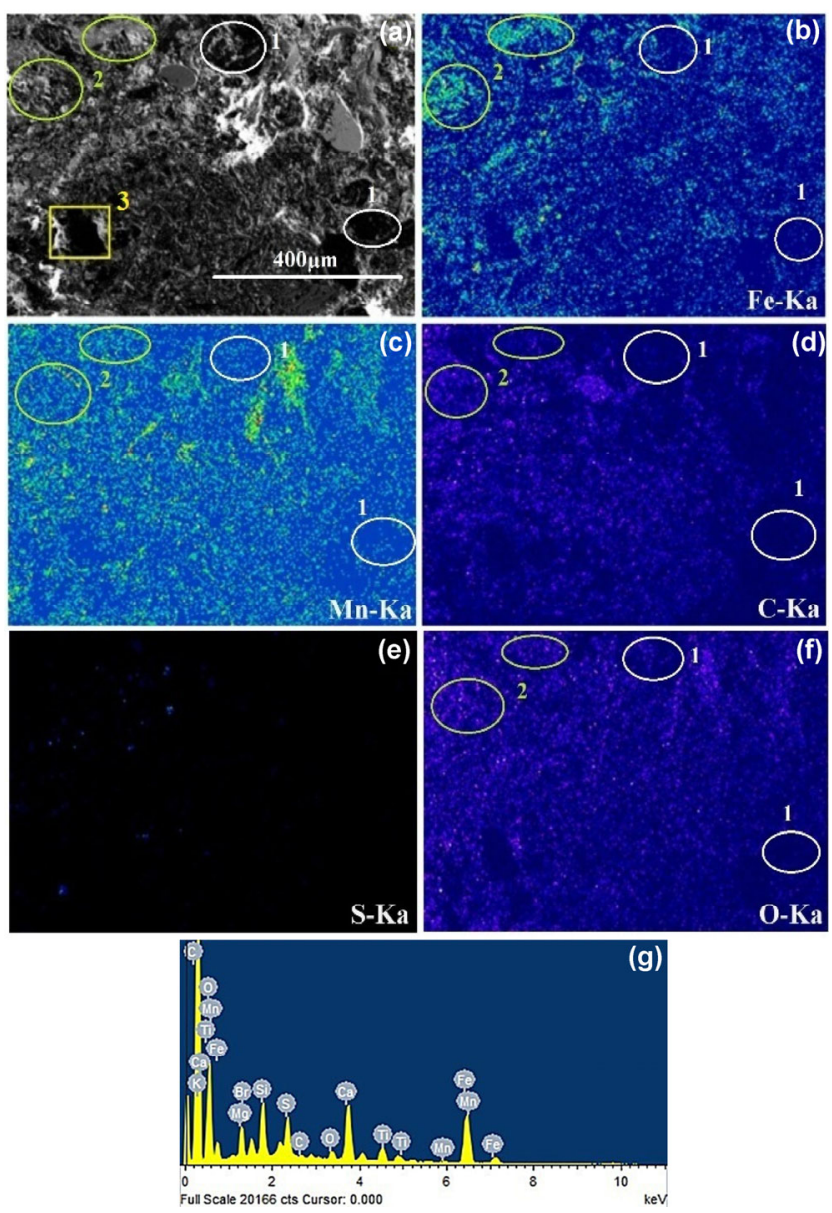

Fig. 13 Worn surfaces of the FM02 composites (a) electron image, (b)-(f) electron images with elemental mapping, and (g) EDAX spectra representing primary plateau composition. 
The 3D surface profile of the dyno tested FM01 and FM02 composites are shown in Figs. 14(a) and 14(b) respectively. The surface roughness was more in the FM01, which is due to more wear causing undulations on the surface. It is seen in Fig. 14(a) that 3D profile showed less blue peaks, which confirms that the load-bearing capacity is less and it does not enhance the friction. While in the case of the FM02 as shown in Fig. 14(b) where the opposite behavior is seen. The blue peaks denote the contact plateaus and abrasion tracks showing the sliding [36]. The surface roughness of the FM02 is $2.0 \mu \mathrm{m}$, but for FM01 it is $2.5 \mu \mathrm{m}$. Similarly, the higher value of surface roughness corresponds to the wear due to fiber tear, abrasion, etc. in the larger amount as reported by other researchers [38]. Thus, the FM02 is a good performer in worn surface characterizations, due to its better friction and wear behavior.

\subsection{Corrosion behavior of developed friction composites}

The corrosion behavior of the developed friction composites is shown in Figs. 15(a)-15(j). When the steel fibers are subjected to corrosion, initially there is an increase in the weight of the fiber in the presence of a medium and due to the presence of oxide ions. It adheres to its surface and forms the ferric oxide,
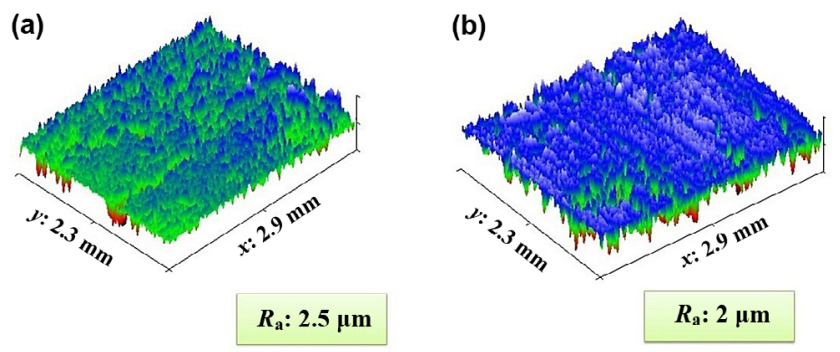

Fig. 14 3D surface profiles of the dyno tested (a) FM01 composite and (b) FM02 composite. which possesses rusting nature. Once the sample is removed from the medium, there is a decrease in weight which is due to rusting of the materials left as the residue in the solution. The samples tested were subjected to weight change, and the same is reported in Table 4.

This type of behavior was mainly seen in humidity, $\mathrm{NaCl}$ and normal water-based testing only. In the case of Brake fluid oil dipped test, there is no change in weight. Generally, when the composite samples are subjected to the fluid medium, there is the absorption of fluid in the samples. However, in the present work, it was not seen as the sample once obtained from the solution medium is wiped off using a clean cloth to remove the excess fluid on its surface and then it is kept in a vacuum desiccator for 2 hours, and after that, it is weighed. It is also clear from the water swell test that the developed samples do not swell when subjected to the liquid environment. Generally, in the case of steel, the iron present in steel loses some electrons to become positively charged materials [39]. This, in turn, reacts with oxygen and water molecules to form iron hydroxide as shown in Eq. (2).

The oxygen is readily available in water in excess quantity, which reacts with the iron hydroxide. This produces hydrated iron oxide commonly known as brown rust as shown in Eq. (3). This brown rust is seen in Fig. 15(c) which is denoted by the circles, in the case of the 3D profile. It is clear from the depth of the profile that a similar trend was seen in Djafri et al. [40]. In the case of $5 \% \mathrm{NaCl}$ based solution, chloride ion possessing negatively charged reacts destructively with the oxide layer [41]. The anion concentration in the electrolyte is an important factor concerning the electrolyte behavior of protector (the oxide that is formed at the top steel surface) [42]. Thus, it is too sensitive to form the present iron oxide layer. The iron which reacts with the oxygen present in the salt

Table 4 Change in weight before and after various test conditions.

\begin{tabular}{ccccc}
\hline \multirow{2}{*}{ Test environment } & \multicolumn{2}{c}{ FM01 (Sample weight) } & \multicolumn{2}{c}{ FM02(Sample weight) } \\
\cline { 2 - 5 } & Before test in grams & After test in grams & Before test in grams & After test in grams \\
\hline Normal water & 14.3217 & 14.2073 & 14.1561 & 14.1559 \\
NaCl solution & 14.4465 & 14.2125 & 14.2319 & 14.2318 \\
Dot-3 brake oil & 14.0173 & 14.0172 & 13.9686 & 13.9685 \\
Humidity chamber & 14.2176 & 14.1031 & 13.9543 & 13.9540 \\
\hline
\end{tabular}



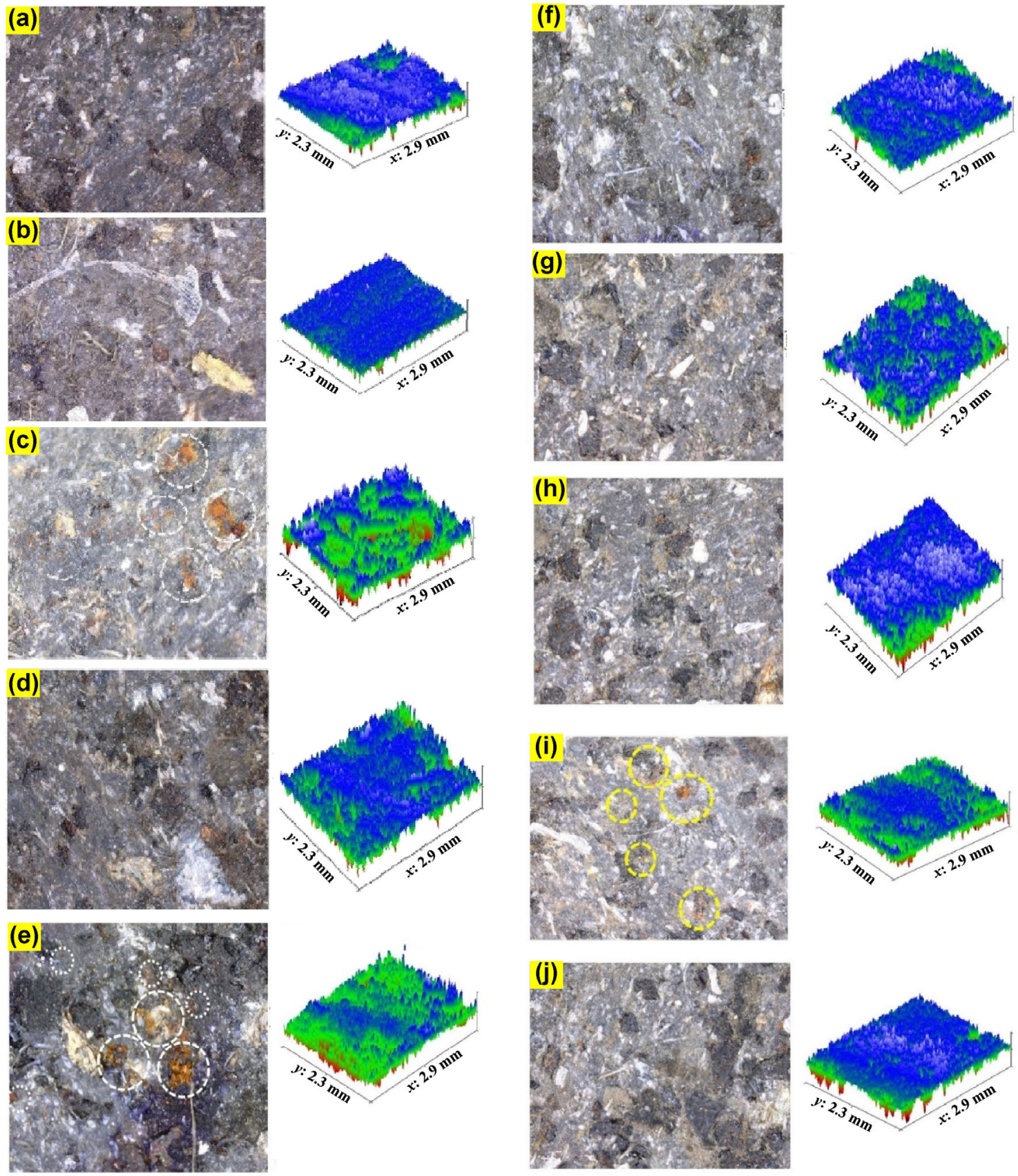

Fig. 15 Microscopic and 3D surface profiles of (a) virgin FM01 sample, (b) virgin FM02 sample, (c) normal water tested FM01 sample, (d) normal water tested FM02 sample, (e) NaCl solution tested FM01 sample, (f) NaCl solution tested FM02 sample, (g) brake oil tested FM01 sample, (h) brake oil tested FM02 sample, (i) humidity tested FM01 sample, and (j) humidity tested FM02 sample.

solution made up of water to form the ferric hydroxide. This further reacts with the more dissolved oxygen to form a ferric oxide, which forms rust. The chloride ion present in the solution reacts more with the oxide layer forming the chloride-based layer, leading to more corrosion of the substance. Thus, from Figs. 15(c) and 15(e), it is apparent that corrosion is more in the case of the FM01, the steel fiber-based composites. Another fact is that in the case of FM01, more surface variations were observed due to the presence of hard reinforcing materials in the matrix, which would also induce flaws leading to more pitting corrosion. This is similar to the findings of Alaneme and Bodunrin [43]. There is a reduction in weight of the tested composite as 
shown in Table 4 . These surface variations are seen in Fig. 15(a) virgin samples of the FM01. Thus, it is visible from the microscopic images and $3 \mathrm{D}$ profile that the FM01 materials are corroded, due to the presence of steel fiber content by its pitting and undulations with red and green color in 3D images. The $\mathrm{pH}$ was measured in all cases before and after the test to confirm that the effect was only due to the material reaction and not by any external factor. It was also discussed by Alaneme and Bodunrin [43] explaining that $\mathrm{pH}$ value would vary slightly upon an increase in the exposure time but will remain constant throughout the test. There is no formation of rust in the FM02 composites which is due to the presence of stainless steel fibers that possess chromium content the $\mathrm{t}$ helps to prevent the attack of fluid medium that causes corrosion by forming a protective layer. In the case of the brake fluid oil-dipped samples, the sample does not cause any pitting corrosion compared to others as seen in Table 4 .

$$
\begin{aligned}
& 2 \mathrm{Fe}+\mathrm{O}_{2}+2 \mathrm{H}_{2} \mathrm{O} \rightarrow 2 \mathrm{Fe}(\mathrm{OH})_{2} \\
& 4 \mathrm{Fe}(\mathrm{OH})_{2}+\mathrm{O}_{2} \rightarrow 2 \mathrm{H}_{2} \mathrm{O}+2 \mathrm{Fe}_{2} \mathrm{O}_{3}
\end{aligned}
$$

This FM02 and FM01 prove that brake samples are not affected by the oil. The surfaces are shown in Figs. 15(g) and 15(h), where there are small deviations in peaks. These are mainly due to the grinding of the samples done at the end of manufacturing and also due to the ingredients which are present on the surface. In the case of humidity tested composites, there were more pits in the case of FM01 samples, which are evident from the 3D profile as shown in Fig. 15(i). The encircled region in the microscopic images shows the pitting formation. Light green color depicts the depth of the pits in 3D surface profile. It is very clear from the previous studies of Chau et al. [8] that zeolite coated steel fiber-based friction materials are treated in nitric acid and compared with the bare steel fiberbased friction composites. It was observed that bare steel fiber-based composites formed the more corrosive layer, while the zeolite coated remained unreacted.

\subsection{Extension evaluation method for ranking the developed friction composites}

The ranking of the developed brake friction composites was done based on extension evaluation method (EEM) procedure. The EEM helps for general ranking/selection of the friction composites. This procedure will be helpful in decision-making tool for the developers (formulation makers), manufacturers and end users [44]. This procedure uses weighed average-dependent degree which is defined as the friction stability of the composites that can be used to compare the quality and to rank them accordingly. Thus, it is assumed there is an interval $X=\langle a, b\rangle$ and a point $M \in X$, the dependent function of any point $x \in(-\infty,+\infty)$, for the interval $X$ and ' $M$ ' point is expressed as given below in Eq. (4).

$$
k(x)= \begin{cases}\frac{x-a}{M-a}, & x \leq M \\ \frac{b-x}{b-M}, & x \geq M\end{cases}
$$

Then, the basic dependent function $k(x)$ has the following properties:

(a) $k(x)$ reaches its maximum at point $x=M$, and $k(x)=1$;

(b) $x \in X$ and $x \neq a, b \leftrightarrow K(x)>0$;

(c) $x \notin X$ and $x \neq a, b \leftrightarrow K(x)<0$;

(d) $x=a$ or $b \leftrightarrow K(x)=0$.

In the case of tribological performance where the brake factor of different tests are ranked and in which $x$ is the brake factor, the dependent function reached its maximum at the middle point of the interval $(M=(a+b) / 2)$. Then the dependent function is expressed using the following Eq. (5).

$$
k(x)=\left\{\begin{array}{l}
\frac{2(x-a)}{b-a}, x \leq \frac{a+b}{2} \\
\frac{2(b-x)}{b-a}, x \geq \frac{a+b}{2}
\end{array}\right.
$$

Upon substituting the brake factor values, the typical dependent function for unbedded performance at $50 \mathrm{kmph}$ is given in Eq. (6).

Unbedded performance at $50 \mathrm{~km} / \mathrm{h}$ is

$$
k b 1(x)=\sum_{i=1}^{7} \alpha_{i} k\left(x_{i}\right) ; \alpha_{1}=\alpha_{2}=\ldots=\alpha_{7}
$$

Similarly, all the other tribo-performance testing with results which are also brake factors are solved by substituting into Eq. (5). The following results are obtained as shown in Table 5. 
Table 5 Results of extensive evaluation of developed composites based on various friction (brake factor) testing.

\begin{tabular}{clll}
\hline S/No. & \multicolumn{1}{c}{ Dependent function determination for various brake factor testing } & FM01 & FM02 \\
\hline 1 & Unbedded performance at $50 \mathrm{kmph}(k b 1(x))$ & 0.2214 & 0.4505 \\
2 & Unbedded performance at $100 \mathrm{kmph}(k b 2(x))$ & 0.5190 & 0.5291 \\
3 & Bedded performance at $30 \mathrm{kmph}(k b 3(x))$ & 0.3697 & 0.3497 \\
4 & Bedded performance at $50 \mathrm{kmph}(k b 4(x))$ & 0.3830 & 0.3991 \\
5 & Bedded performance at $80 \mathrm{kmph}(k b 5(x))$ & 0.4038 & 0.4301 \\
6 & Bedded performance at $100 \mathrm{kmph}(k b 6(x))$ & 0.3742 & 0.4354 \\
7 & Bedded performance at $112 \mathrm{kmph}(k b 7(x))$ & 0.4082 & 0.4029 \\
8 & Bedded performance at $120 \mathrm{kmph}(k b 8(x))$ & 0.3736 & 0.4919 \\
9 & Bedded performance at $140 \mathrm{kmph}(k b 9(x))$ & 0.4070 & 0.3687 \\
10 & Bedded performance at $150 \mathrm{kmph}(k b 10(x))$ & 0.4906 & 0.4163 \\
11 & Fade test $(k b 11(x))$ & 0.4106 & 0.4589 \\
12 & Recovery test $(k b 12(x))$ & 0.3077 & 0.4633 \\
13 & Brake jamming test $($ before water spray) $(k b 13(x))$ & 0.0629 & 0.6222 \\
14 & Brake jamming test $($ after water spray) $(k b 14(x))$ & 0.6394 & 0.1561 \\
15 & Wet recovery $(k b 15(x))$ & 0.6402 & \\
\hline
\end{tabular}

As we have seen in the before sections that negative fade rate (drastically varying with FM02) is noticed in FM01, this results in higher dependent function value during this solving in case of $k b 11(x)$ for FM01 in that particular case.

To find the overall $k b(x)$ for the brake factor calculation, the Eq. (7) is used.

$$
k b(x)=\frac{k b 1(x)+k b 2(x)+\ldots+k b 14(x)+k b 15(x)}{15}
$$

Upon substituting the Table 5 values in Eq. (6), we get $k b(x)$ for FM01 as 0.3814 and FM02 as 0.4427 .

Then the developed composites were evaluated based on the wear performance using the test results obtained from Section 3.2.5. The wear rate is measured in the form of thickness loss, and the individual intervals are $\langle a, b\rangle$, where each value in the interval has the same weight. The maximum value is reached for the dependent function when the wear rate is lower. The dependent function is thus given by the following Eq. (8) [45].

$$
k(x)=\left\{\begin{array}{cc}
\frac{x-a}{M-a}, & x \leq M \\
1, & x=a \\
\frac{b-x}{b-M}, & x \geq M
\end{array}\right.
$$

Five values are obtained for each test, each side (LHS and RHS), each edge (leading and trailing), and each composite (FM01 and FM02). Based on the test results in value by substituting in Eq. (8), the dependent function is calculated for various wear tests and tabulated in Table 6. The typical equation for performance testing trailing edge LHS side is shown in Eq. (9).

$$
k w 1(x)=\sum_{i=1}^{5} \delta_{i} k\left(x_{i}\right) ; \quad \delta_{1}=\delta_{2}=\ldots=\delta_{5}
$$

To find the overall wear dependent function $k w(x)$ for the tested composites, the Eq. (10) is used.

$$
k w(x)=\frac{k w 1(x)+k w 2(x)+\ldots+k w 19(x)+k w 20(x)}{20}
$$

Upon substituting the table 6 values in Eq. (9), we get $k w(x)$ for FM01 as 0.5732 and FM02 as 0.5364 . The wear rate should be lower for ideal friction materials, FM02 showed such behavior. In table 6, in S/No. 6, 9, 11, 17, and 18 in which FM02 showed higher dependent function than FM01 which are due to more different values in the composites as seen in Fig. 10. 
Table 6 Results of extensive evaluation of developed composites based on various wear tests.

\begin{tabular}{|c|c|c|c|}
\hline S/No. & Dependent function for various wear testing & FM01 & FM02 \\
\hline 1 & Performance testing trailing edge LHS side $(k w 1(x))$ & 0.6679 & 0.5895 \\
\hline 2 & Performance testing trailing edge RHS side $(k w 2(x))$ & 0.6223 & 0.4400 \\
\hline 3 & Performance testing leading edge LHS side $(k w 3(x))$ & 0.7068 & 0.4917 \\
\hline 4 & Performance testing leading edge RHS side $(k w 4(x))$ & 0.4647 & 0.6765 \\
\hline 5 & Wear test at $80-30 \mathrm{kmph}$ at $200{ }^{\circ} \mathrm{C}$ leading edge LHS side $(k w 5(x))$ & 0.5802 & 0.5400 \\
\hline 6 & Wear test at $80-30 \mathrm{kmph}$ at $200{ }^{\circ} \mathrm{C}$ leading edge RHS side $(k w 6(x))$ & 0.5447 & 0.6143 \\
\hline 7 & Wear test at $80-30 \mathrm{kmph}$ at $200{ }^{\circ} \mathrm{C}$ trailing edge LHS side $(k w 7(x))$ & 0.5614 & 0.5000 \\
\hline 8 & Wear test at $80-30 \mathrm{kmph}$ at $200{ }^{\circ} \mathrm{C}$ trailing edge RHS side $(k w 8(x))$ & 0.5347 & 0.5833 \\
\hline 9 & Wear test at $90-40 \mathrm{kmph}$ at $200{ }^{\circ} \mathrm{C}$ leading edge LHS side $(k w 9(x))$ & 0.4943 & 0.6375 \\
\hline 10 & Wear test at $90-40 \mathrm{kmph}$ at $200{ }^{\circ} \mathrm{C}$ leading edge RHS side $(k w 10(x))$ & 0.6022 & 0.4000 \\
\hline 11 & Wear test at $90-40 \mathrm{kmph}$ at $200{ }^{\circ} \mathrm{C}$ trailing edge LHS side $(k w 11(x))$ & 0.5918 & 0.7045 \\
\hline 12 & Wear test at $90-40 \mathrm{kmph}$ at $200{ }^{\circ} \mathrm{C}$ trailing edge RHS side $(k w 12(x))$ & 0.6543 & 0.4970 \\
\hline 13 & Wear test at $100-50 \mathrm{kmph}$ at $200{ }^{\circ} \mathrm{C}$ leading edge LHS side $(k w 13(x))$ & 0.5708 & 0.4500 \\
\hline 14 & Wear test at $100-50 \mathrm{kmph}$ at $200^{\circ} \mathrm{C}$ leading edge RHS side $(k w 14(x))$ & 0.5080 & 0.4143 \\
\hline 15 & Wear test at $100-50 \mathrm{kmph}$ at $200^{\circ} \mathrm{C}$ trailing edge LHS side $(k w 15(x))$ & 0.6429 & 0.5311 \\
\hline 16 & Wear test at $100-50 \mathrm{kmph}$ at $200^{\circ} \mathrm{C}$ trailing edge RHS side $(k w 16(x))$ & 0.6232 & 0.4048 \\
\hline 17 & Wear test at $110-60 \mathrm{kmph}$ at $200^{\circ} \mathrm{C}$ leading edge LHS side $(k w 17(x))$ & 0.4103 & 0.5385 \\
\hline 18 & Wear test at $110-60 \mathrm{kmph}$ at $200^{\circ} \mathrm{C}$ leading edge RHS side $(k w 18(x))$ & 0.402 & 0.6933 \\
\hline 19 & Wear test at $110-60 \mathrm{kmph}$ at $200^{\circ} \mathrm{C}$ trailing edge LHS side $(k w 19(x))$ & 0.7026 & 0.4892 \\
\hline 20 & Wear test at $110-60 \mathrm{kmph}$ at $200^{\circ} \mathrm{C}$ trailing edge RHS side $(k w 20(x))$ & 0.5784 & 0.5313 \\
\hline
\end{tabular}

Based on the results of $k b(x)$ and $k w(x)$ (brake factor and wear rate), the weighted average dependent degree $k_{\text {overall }}(x)$ which describes the overall quality of the developed composite is determined using Eq. (11).

$$
k_{\text {overall }}(x)=k b(x)+k w(x)
$$

By substituting the desired values obtained from Eqs. (7) and (10) in Eq. (11), we get koverall( $x$ ) for FM01 as 0.4773 and FM02 as 0.4896 . Higher the koverall, better the composites. Based on these results, FM02 rank's first and it is superior in quality when compared to FM01.

\section{Conclusions}

Based on the studies of steel fiber (FM01) and stainless steel fiber (FM02) based friction composites, it was revealed that stainless steel fiber-based friction composites confirmed good brake performance characteristics with positive fade, less drum, and less liner wear. While in the case of steel fiber-based friction composites, it produced negative fade, aggressive drum, and liner wear, thereby increasing the temperature and consequently causing more thermal stress. SEM and elemental mapping studies of steel fiber-based friction composites visualized more back transfer of polymeric ingredients in combination with drum wear debris due to high-temperature rise caused by the abrasive action of steel fibers. Corrosion studies showed that steel fiber-based friction composites are liable to pitting and oxidation corrosion due to their steel fiber content. Thus, the FM02 composites possessing stainless steel fiber as a variable ingredient in the friction composite formulation could be a positive alternative solution for the problems caused by steel fiber-based friction composites, and this was proved using extensive evaluation method of ranking.

\section{Appendix}

Appendix I- Manufacturing methodology involved in the development of brake liner is given below in Table A1. 
Table A1 Manufacturing methodology.

\begin{tabular}{|c|c|c|}
\hline S/No. & Process & Parameter \\
\hline \multirow{6}{*}{1} & \multicolumn{2}{|l|}{ Mixing process } \\
\hline & Machine & Lodigie machine \\
\hline & $\begin{array}{l}\text { Cutter speed; } \\
\text { shovel speed }\end{array}$ & $3,000 \mathrm{rpm} ; 140 \mathrm{rpm}$ \\
\hline & Mix quantity & $10 \mathrm{~kg}$ \\
\hline & Mixing time & 20 minutes \\
\hline & Mixing sequence & $\begin{array}{l}\text { Fibers- } 5 \text { minutes (after the pre- } \\
\text { opening of aramid with hydrated } \\
\text { lime for } 15 \text { minutes) } \\
\text { Binders }-4 \text { minutes } \\
\text { Friction modifiers and fillers- } \\
11 \text { minutes }\end{array}$ \\
\hline \multirow{4}{*}{2} & \multicolumn{2}{|l|}{ Preform process } \\
\hline & Machine & Hydraulic press \\
\hline & $\begin{array}{l}\text { Preform weight; } \\
\text { pressure }\end{array}$ & 600 grams for six liners; $15.2 \mathrm{MPa}$ \\
\hline & $\begin{array}{l}\text { Cycle time } \\
\text { (compression) }\end{array}$ & 10 seconds \\
\hline \multirow{6}{*}{3} & \multicolumn{2}{|l|}{ Curing process } \\
\hline & Machine & Compression molding machine \\
\hline & $\begin{array}{l}\text { Curing pressure; } \\
\text { temperature }\end{array}$ & $20.7 \mathrm{MPa} ; 145-155^{\circ} \mathrm{C}$ \\
\hline & Total cycle time & 480 seconds (6 minutes) \\
\hline & $\begin{array}{l}\text { Cycle time at } \\
\text { breathing }\end{array}$ & 133 seconds ( 5 breathings) \\
\hline & Final curing time & 227 seconds \\
\hline
\end{tabular}

Post-curing process

Machine Hot air oven (step baking process)

4 Ambient to $160^{\circ} \mathrm{C}$ rise

Temperature (30 minutes); at $160{ }^{\circ} \mathrm{C}$

range (3 hours); a rise from 160 to

(with time) $\quad 180{ }^{\circ} \mathrm{C}\left(30\right.$ minutes); at $180{ }^{\circ} \mathrm{C}$

(3 hours)

\section{Appendix II}

(a) Formulas used for calculating test parameters

The formulas used for calculating the different values are given below in the Eqs. (A1)-(A5).

Brake factor $=$ Drum drag $/$ STE

Drum drag $=$ Brake torque $(B T) /$ Effective radius

of $\operatorname{drum}(R)$
STE (shoe tip effectiveness) $=$ Input pressure $(P)$ *

Effective area of wheel cylinder $(A)$

$P=$ Input pressure to brake system - Threshold pressure (3.5)

$A=3.14 / 4$ * (wheel cylinder piston diameter) ${ }^{2}$ *

Number of pistons

(b) Coefficient of friction vs. brake factor plot

Brake factor is dependent on the following parameters namely

- The coefficient of friction between drum and lining

- The arc length and angular position of the lining

- The type and position of the shoe mounting, i.e., pinned or sliding

- The position and angle of the abutment

- The brake factor is correlated with the coefficient of friction based on Fig. $A_{1}$.

The curve considered for this present work is simplex-hydraulic (solid blue line).

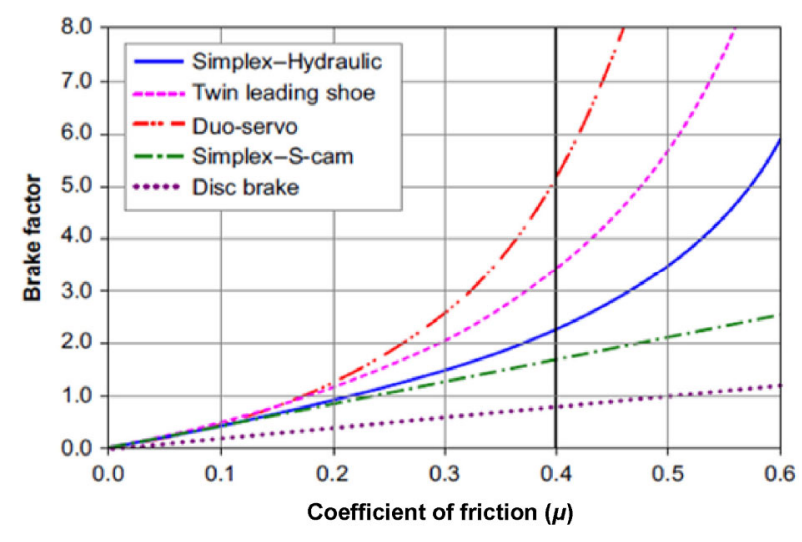

Fig. A Coefficient of friction vs. brake factor.

\section{Acknowledgements}

Authors express their gratitudes to Mr. Samit Singhai, Kasturi Metal Composites Private Limited, Amravati, Maharashtra, India, for providing the steel and stainless fibers. Authors also thank the well-wisher(s) who have helped in manufacturing and testing of these friction composites.

Open Access This article is licensed under a Creative Commons Attribution 4.0 International License, which permits use, sharing, adaptation, distribution and reproduction in any medium or format, as long as 
you give appropriate credit to the original author(s) and the source, provide a link to the Creative Commons licence, and indicate if changes were made.

The images or other third party material in this article are included in the article's Creative Commons licence, unless indicated otherwise in a credit line to the material. If material is not included in the article's Creative Commons licence and your intended use is not permitted by statutory regulation or exceeds the permitted use, you will need to obtain permission directly from the copyright holder.

To view a copy of this licence, visit http://creativecommons.org/licenses/by/4.0/.

\section{References}

[1] Chan D, Stachowiak G W. Review of automotive brake friction materials. Proc Inst Mech Eng Part D: J Automob Eng 218(9): 953-966 (2004)

[2] Lenin Singaravelu D, Vijay R, Rahul M. Influence of crab shell on tribological characterization of eco-friendly products based non asbestos brake friction materials. In SAE Technical Paper, Charleston, USA, 2015.

[3] Bijwe J, Kumar M. Optimization of steel wool contents in non-asbestos organic (NAO) friction composites for best combination of thermal conductivity and tribo-performance. Wear 263(7-12): 1243-1248 (2007)

[4] Jang H, Ko K, Kim S J, Basch R H, Fash J W. The effect of metal fibers on the friction performance of automotive brake friction materials. Wear 256(3-4): 406-414 (2004)

[5] Park S B, Cho K H, Jung S, Jang H. Tribological properties of brake friction materials with steel fibers. Met Mater Int 15(1): 27-32 (2009)

[6] Kumar M, Bijwe J. Role of different metallic fillers in nonasbestos organic (NAO) friction composites for controlling sensitivity of coefficient of friction to load and speed. Tribol Int 43(5-6): 965-974 (2010)

[7] Thiyagarajan V, Kalaichelvan K, Vijay R, Lenin S D. Influence of thermal conductivity and thermal stability on the fade and recovery characteristics of non-asbestos semi-metallic disc brake pad. J Braz Soc Mech Sci Eng 38(4): 1207-1219 (2016)

[8] Chau J L H, Lee C C, Yang C C, Shih H H. Zeolite-coated steel fibers for friction materials applications. Proc Inst Mech Eng Part L: J Mater: Des Appl 230(1): 35-42 (2016)

[9] Day A. Braking of Road Vehicles. Amsterdam (the Netherlands): Butterworth-Heinemann, 2014: 131.

[10] Jaafar T R, Selamat M S, Kasiran R. Selection of best formulation for semi-metallic brake friction materials development. Geneva (Switzerland): IntechOpen Access Publisher, 2012.

[11] Kumar M, Satapathy B K, Patnaik A, Kolluri D K, Tomar B S. Hybrid composite friction materials reinforced with combination of potassium titanate whiskers and aramid fibre: assessment of fade and recovery performance. Tribol Int 44(4): 359-367 (2011)

[12] Fu H, Liao B, Qi F J, Sun B C, Liu A P, Ren D L. The application of PEEK in stainless steel fiber and carbon fiber reinforced composites. Compos Part B: Eng 39(4): 585-591 (2008)

[13] Bijwe J, Kumar M, Gurunath P V, Desplanques Y, Degallaix G. Optimization of brass contents for best combination of tribo-performance and thermal conductivity of non-asbestos organic (NAO) friction composites. Wear 265(5-6): 699-712 (2008)

[14] Fu H, Fu L, Zhang G L, Wang R M, Liao B, Sun B C. Abrasion mechanism of stainless steel/carbon fiber-reinforced polyether-ether-ketone (PEEK) composites. J Mater Eng Perform 18(7): 973-979 (2009)

[15] Wang F H, Liu Y. Mechanical and tribological properties of ceramic-matrix friction materials with steel fiber and mullite fiber. Mater Des 57: 449-455 (2014)

[16] El-Tayeb N S M, Liew K W. On the dry and wet sliding performance of potentially new frictional brake pad materials for automotive industry. Wear 266(1-2): 275-287 (2009)

[17] Aranganathan N, Bijwe J. Development of copper-free eco-friendly brake-friction material using novel ingredients. Wear 352-353: 79-91 (2016)

[18] Kumar M, Bijwe J. Optimized selection of metallic fillers for best combination of performance properties of friction materials: A comprehensive study. Wear 303(1-2): 569-583 (2013)

[19] Kumar M, Bijwe J. Composite friction materials based on metallic fillers: sensitivity of $\mu$ to operating variables. Tribol Int 44(2): 106-113 (2011)

[20] Blau P J, McLaughlin J C. Effects of water films and sliding speed on the frictional behavior of truck disc brake materials. Tribol Int 36(10): 709-715 (2003)

[21] Magnier V, Roubin E, Colliat J B, Dufrénoy P. Methodology of porosity modeling for friction pad: consequence on squeal. Tribol Int 109: 78-85 (2017)

[22] Ji Z J, Jin H Y, Luo W Y, Cheng F R, Chen Y, Ren Y Z, $\mathrm{Wu}$ Y Q, Hou S E. The effect of crystallinity of potassium titanate whisker on the tribological behavior of NAO friction materials. Tribol Int 107: 213-220 (2017)

[23] Timur M, Kuşçu H. Heat transfer of brake pad used in the autos after friction and examination of thermal tension analysis. Mechanics 20(1): 17-23 (2014)

[24] Cai P, Wang T M, Wang Q H. Sensitivity of $\mu$ of friction 
materials to load and speed under dry sliding and water lubricated conditions. Tribol Trans 59(2): 300-308 (2016)

[25] El-Tayeb N S M, Liew K W. Effect of water spray on friction and wear behaviour of noncommercial and commercial brake pad materials. J Mater Process Technol 208(1-3): 135-144 (2008)

[26] Eriksson M, Lundqvist A, Jacobson S. A study of the influence of humidity on the friction and squeal generation of automotive brake pads. Proc Inst Mech Eng Part D: J Automob Eng 215(3): 329-342 (2001)

[27] Olofsson U, Sundh J, Bik U, Nilsson R. The influence of snow on the tread braking performance of a train: A pin-on-disc simulation performed in a climate chamber. Proc Inst Mech Eng Part F: J Rail Rapid Transit 230(6): 1521-1530 (2016)

[28] Wang F, Gu K K, Wang W J, Liu Q Y, Zhu M H. Study on braking tribological behaviors of brake shoe material under the wet condition. Wear 342-343: 262-269 (2015)

[29] Österle W, Dörfel I, Prietzel C, Rooch H, Cristol-Bulthé A L, Degallaix G, Desplanques Y. A comprehensive microscopic study of third body formation at the interface between a brake pad and brake disc during the final stage of a pin-on-disc test. Wear 267(5-8): 781-788 (2009)

[30] Österle W, Urban I. Friction layers and friction films on PMC brake pads. Wear 257(1-2): 215-226 (2004)

[31] Qu X W, Zhang L C, Ding H L, Liu G D. The effect of steel fiber orientation on frictional properties of asbestos-free friction materials. Polym Compos 25(1): 94-101 (2004)

[32] Xiao X M, Yin Y, Bao J S, Lu L J, Feng X J. Review on the friction and wear of brake materials. Adv Mech Eng 8(5): 1-10 (2016)

[33] Kolluri D K, Ghosh A K, Bijwe J. Performance evaluation of composite friction materials: Influence of nature and particle size of graphite. J Reinf Plast Comp 29(18): 2842-2854 (2010)

[34] Sellami A, Kchaou M, Elleuch R, Cristol A L, Desplanques Y. Study of the interaction between microstructure, mechanical and tribo-performance of a commercial brake lining material.

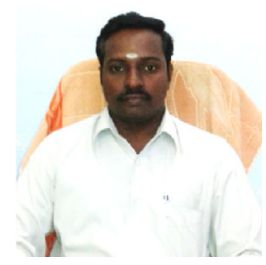

D. Lenin SINGARAVELU. He is working as an associate professor in the Department of Production Engineering, National Institute of Technology Tiruchirappalli, Tamil Nadu, India. He obtained his Ph.D. in the field of friction materials in Metallurgical and Materials Engineering Department from IIT Roorkee.
Mater Des 59: 84-93 (2014)

[35] Matějka V, Lu Y F, Fan Y L, Kratošová G, Lešková J. Effects of silicon carbide in semi-metallic brake materials on friction performance and friction layer formation. Wear 265(7-8): 1121-1128 (2008)

[36] Neis P D, Ferreira N F, Fekete G, Matozo L T, Masotti D. Towards a better understanding of the structures existing on the surface of brake pads. Tribol Int 105: 135-147 (2017)

[37] Aranganathan N, Bijwe J. Special grade of graphite in NAO friction materials for possible replacement of copper. Wear 330-331: 515-523 (2015)

[38] Ilanko A K, Vijayaraghavan S. Wear behavior of asbestos-free eco-friendly composites for automobile brake materials. Friction 4(2): 144-152 (2016)

[39] Nimmo B, Hinds G. Beginners Guide to Corrosion. Teddington (UK): NPL's Corrosion Group, 2003.

[40] Djafri M, Bouchetara M, Busch C, Weber S. Effects of humidity and corrosion on the tribological behaviour of the brake disc materials. Wear 321: 8-15 (2014)

[41] Asaduzzaman M D, Mohammad C M, Mayeedul I. Effects of concentration of sodium chloride solution on the pitting corrosion behavior of AISI 304L austenitic stainless steel. Chem Ind Chem Eng Quart 17(4): 477-483 (2011)

[42] Ihom A P, Nyior G B, Nor Iv J, Segun S, Ogbodo J. Evaluation of the corrosion resistance of aluminum alloy matrix $/ 2.5 \%$ particulate glass reinforced composite in various media. Int J Sci Technol 1(10): 560-568 (2012)

[43] Alaneme K K, Bodunrin M O. Corrosion behavior of alumina reinforced aluminium (6063) metal matrix composites. J Miner and Mater Charact Eng 10(12): 1153-1165 (2011)

[44] Yun R P, Filip P, Lu Y F. Performance and evaluation of eco-friendly brake friction materials. Tribol Int 43(11): 2010-2019 (2010)

[45] Qi S C, Fu Z Z, Yun R P, Jiang S L, Zheng X A, Lu Y F, Matejka V, Kukutschova J, Peknikova V, Prikasky M. Effects of walnut shells on friction and wear performance of eco-friendly brake friction composites. Proc Inst Mech Eng Part J: J Eng Tribol 228(5): 511-520 (2014)

He holds an Indian patent in his name in the field of brake friction materials. He has 14 years of research experience and 10 years of teaching experience. His areas of expertise are friction materials, tribology, powder metallurgy, natural fiber composites, processing of polymer products, nonconventional machining, composites processing, and shape memory alloys. 


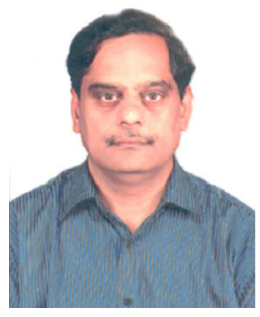

R. JAYAGANTHAN. He is working as a professor in the Department of Engineering Design, Indian Institute of Technology, Madras Tamil Nadu, India. He obtained his Ph.D. in the field of materials engineering from IISC Bangalore, India in 1998.

He had been awarded Alexander Von Humboldt Fellowship by AVH Foundation, Germany in 1998. He

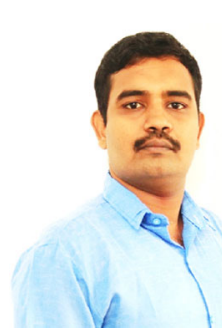

Vijay R. He is currently pursuing Ph.D. in the field of brake friction materials from Department of Production Engineering, National Institute of Technology, Tiruchirappalli, Tamil Nadu, India. He has six years of post-doctoral research experience at Max Planck Institute for Metals Research, Stuttgart, Germany, and National University of Singapore. His area of research includes additive manufacturing, Severe Plastic Deformation (SPD) processing, fatigue $\&$ fracture mechanics, structure-property correlation, structural nanomaterials, and Finite Element Modeling (FEM) simulation.

completed his bachelor in mechanical engineering in 2012 and master in computer integrated manufacturing in 2014 from Anna University, Chennai, India. His area of interest includes brake friction materials, natural fiber composites, and tribology. 